\title{
Geometries of Light and Shadows, from Piero della Francesca to James Turrell
}

\author{
Agostino De Rosa and Francesco Bergamo
}

\section{Contents}

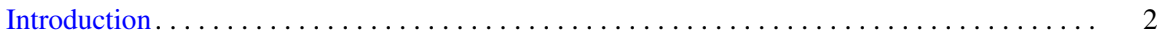

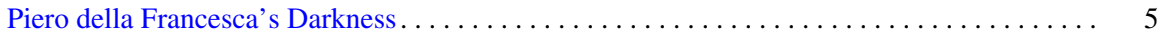

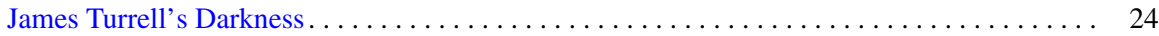

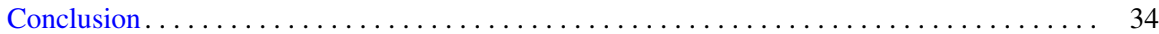

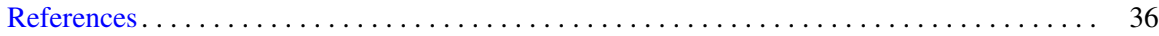

Suggested Further Reading $\ldots \ldots \ldots \ldots \ldots \ldots \ldots \ldots \ldots \ldots \ldots \ldots \ldots \ldots \ldots \ldots \ldots \ldots \ldots$

\begin{abstract}
This chapter addresses the problem of representing light and shadow in the artistic culture, from its uncertain beginnings, related to the studies on conical linear perspective in the Fifteenth Century, to the applications of light projection in the installations of contemporary art.

Here are examined in particular two works by two artists, representing two different conceptual approaches to the perception and symbolism of light and shadow. The first is the so-called Brera Madonna by Piero della Francesca, where the image projected from a luminous radiation is employed with a narrative purpose, supporting the apparently hidden script of the painting and according to the artist's own speculations about perspective as a means to clarify the phenomenal world.

The second is one of James Turrell's Dark Spaces installations, where quantum electrodynamics interpretation of light is taken into account: for Turrell, light is physical and thus can shape spaces where the visitors, or viewers, can "see themselves seeing." In his body of work, perceptual deceptions are carefully
\end{abstract}

\footnotetext{
A. De Rosa $(\triangle) \cdot$ F. Bergamo

Dipartimento di Culture del Progetto, Università Iuav di Venezia, Venezia, Italy

e-mail: aderosa@iuav.it; fraberg@iuav.it
} 
produced by the interaction of the senses with his phenomenal staging of light and darkness, but a strong symbolic component is always present, often related to his own speculative interests.

In both cases, light and shadow, through their geometries, emphasize both phenomenal and spiritual contents of the work of art, intended as a device to expand the perception and the knowledge of the viewer.

\section{Keywords}

Shadow projection - Perspective - Drawing - Piero Della Francesca · James Turrell

\section{Introduction}

In the geometric depiction of the real, the object (or the body) often sacrifices its own existence, ever changing and variable, to the knowledge of the world. In other words, the image of an object upon a two-dimensional support defines the evolutive history of the object itself in a precise spatial and temporal instant. It hangs in the balance between a semantic border with the memory of its past existence, on one side, and the signal of its subtraction from the visible world, on the other side, in favor of entering the universe of graphic projection where the differences between up and down, right and left, tangible and intangible, become geometric conventions instead of phenomenal conditions. The singular utility of this expulsion of life, committed by representation, provokes in our eyes the paradoxically contrary effect that drawn objects still belong to our world, because in this way they are more easily controllable, both perceptively and metrically, and it is possible to use them to organize fragments of reality.

Drawing, as much as writing, identifies itself with a sort of artificial memory, a place outside the mind where the complexity of remembering is transferred: in this way, memory does not dwell any longer in us but can be found instead on a sheet of paper, in graphical signs or inscriptions. "Memory and immanence, what has been and what could happen, form the present of the work" (Rella 1986) thus addresses to describe a space between what we effectively see and what it is possible to see. For this reason, artworks can have the role to represent the unrepresentable, to perceive the unperceivable. Therefore, the operation of representing is activated when something new emerges behind our eyes.

There is a specific kind of projection which translates the object into a thin and planar icon while, at the same time, still following the laws of organic development, enabling the appearance of the aforementioned subliminal landscape: it is the shadow projection. In the phenomenal world, the shadow grows, evolves, and is then reabsorbed by nocturnal darkness. It moves together with the absolute motions of the object and of the light source, and of course with the relative motions of both. In nature, a shadow is given as representation par excellence, replica, clone purified from the stereometrics and physiognomic complexities of the object. A shadow is familiar and present in our daily perceptual world to the point that we almost 
disregard its existence, parallel to our own existence. Silent and loyal, the shadow is inevitably related to an eschatological meaning which allows to investigate its semantic implications even in the context of drawing, that is to say where its essence as an image is sublimated by becoming a drawing according to the methods of Descriptive Geometry (Fig. 1). Here is the meaning of the two case studies here presented: shadow, in its graphical and pictorial representations, is investigated by slowly approaching its most intimate and poetic core. Each provides a general reference framework to read its figurative deployment. Legends, myths, initiatory values of Shadow, as a balance point for the occurring of cosmogonies and rituals, suggest that its phenomenal appearance is pure representation, illusion, echo of a deeper and farther reality, often out of reach.

The history of skiagraphia (the theory of shadows) includes errors and reconsiderations, approximations and attempts, slowly converging towards a "geometric truth" which is often in contrast with the painters' expressive needs. Skiagraphia summarizes the most complex problems faced and solved by Descriptive Geometry. The theory of shadows is, therefore, even before becoming a specific section of the discipline of Geometry, an archetype of the idea of projection and drawing, a place where awareness and prefiguration try to solve a problem which is, apparently, only geometric. Figurative artists have been the privileged actors who dealt with this problem: their works are often true representational tour-de-forces where complex figurative, perspectival, and skiagraphic problems converge. Paintings, extraordinary accumulators of graphical and symbolical signs, are fascinating because of the high concentration of these representational problems upon a limited surface.

The two artworks here presented look deep into these premises. They are specifically emblematic of the staging of skiagraphic problems and of perspectival fruition. The first is the painting also known as Pala di Brera (1472) by the Italian painter Piero della Francesca (1406 or 1412-1492), who wrote extensively about perspective and is famous for the rigorous application to his paintings of the methods he described. But while the reference frame is always clear for painted architectural elements, things become more problematic when it comes to shadows, raising many questions that scholars are still trying to solve, drawing especially from geometrical and projective theories.

The second is the installation Blind Sight (1992) by the American contemporary artist James Turrell (1943-). Turrell is well known, among contemporary artists, for being profoundly expert about the rules and possibilities of geometry, astronomical models, theories on light and visual perception, which he employs to build mathematically tuned environments that enable spectators to become aware of how their perceptual system works. The Dark Spaces series, of which Blind Sight is a significant example, push this approach to its limit by subtracting as much light as possible to the projection of geometrical shapes in total dark.

In both examples, light and shadow are deployed according to geometric rigor and accurate observation of phenomenal reality. But they are also based on unconventional and imaginative choices, dictated by expressive strategies and questions about the ambiguity of perception. In the selected works, both artists 


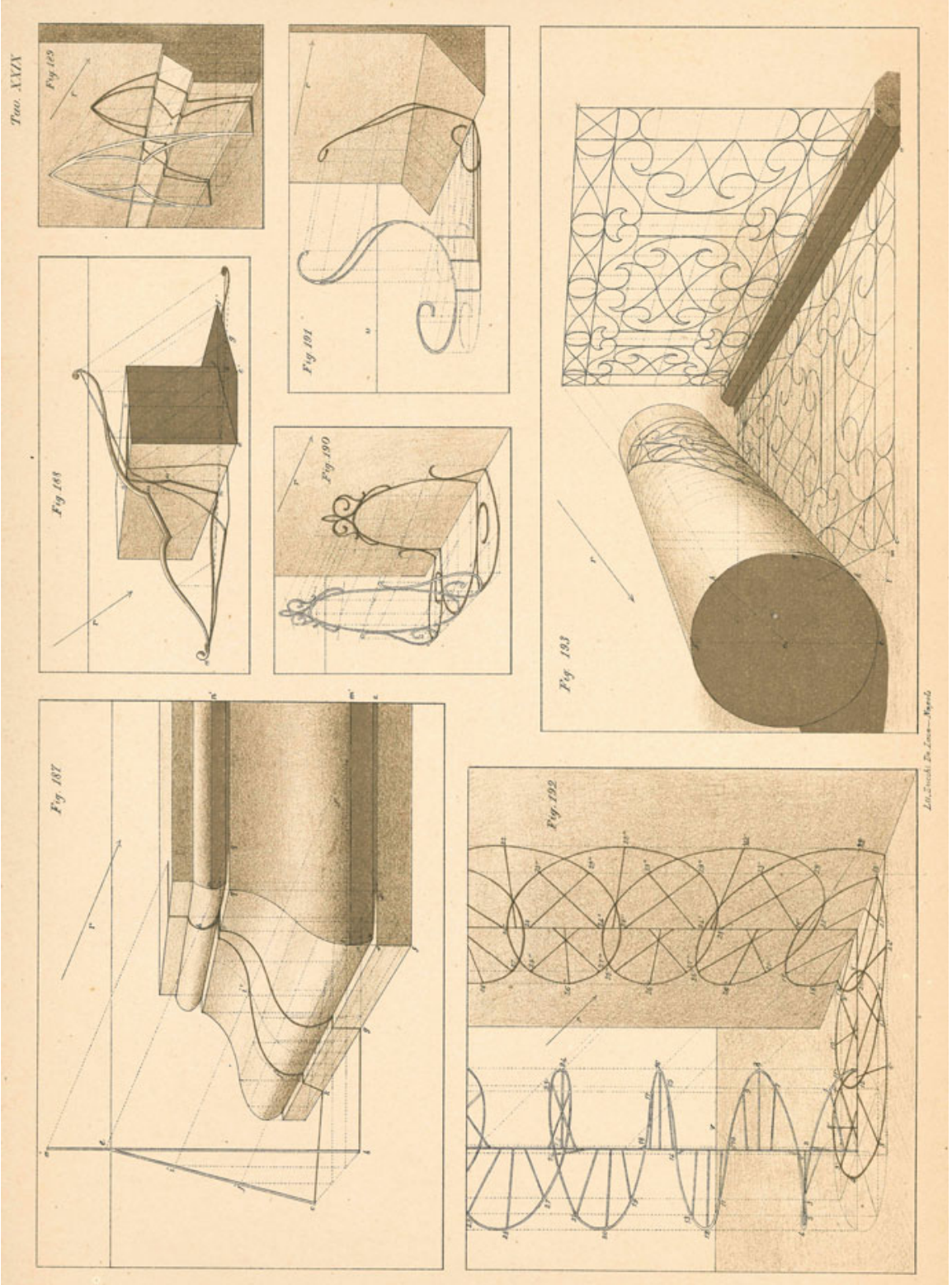

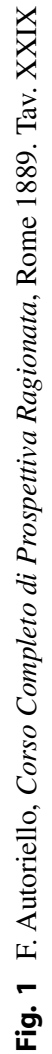


seem to wonder what kind of image has a right to inhabit a representation: is it the sensory, or the intellectualized? This question is extremely important for today's world, bewildered by the dualism between image (as a vehicle of information) and perception (nowadays more and more anesthetized and manipulated).

\section{Piero della Francesca's Darkness}

It is quite difficult to follow the shadow lines in Piero della Francesca's paintings, and the light sources are often hidden. Nonetheless, a few exceptions allow to analyze light and illumination in some of his paintings. In Constantine's Dream (1455; Arezzo, San Francesco Church), the Emperor's sleep during the night before the battle against Maxentius is interrupted by the apparition of an Angel. This nocturnal scene is dramatically marked by strong chiaroscuro effects, characterizing each scenic element and especially the Angel, who apparently stands upon a light beam ascending from the camp below. His gliding pose, with his wings wide open, is underlined by the weave of light and shadow on his profile, probably influenced by works of painters from the Northern Europe. In the Madonna di Senigallia (1470 approx.; Urbino, Galleria Nazionale delle Marche), the windows on the left, behind the male character, allow a beam of sunlight to filter clearly, projecting on the wall a complex arabesque of shadows and reflections generated by the glass washers. Similarly, something interesting happens in the Flagellation of Christ (1470 approx.; Urbino, Galleria Nazionale delle Marche), extensively studied by scholars for its perspectival construction, boasting the highest number of perspectival restitutions ever made on a painting. But perspectival orthodoxy is not its only relevant feature: Aromberg Lavin was able to reverse engineer the complex lighting system which guarantees a further illusory depth, both physical and metaphysical, to the painting (Aromberg Lavin 1972). The large number of evidences collected by scholars proves that Piero was not only a master of geometry in perspective paintings, which is necessary to determine the shadows produced both by artificial light sources and by the Sun; but he was also a master when it came to stage the symbolism implicit in the narrative plots he displayed.

From this point of view, the most interesting painting of his is the famous Brera altarpiece (or Sacred Conversation, Pinacoteca di Brera, Milan) (Fig. 2). Piero della Francesca painted it approximately between 1472 and 1474. This work, originally in the Church of San Bernardino in Urbino, was an absolute iconographic novelty for the Italian artistic circle of the time, because the figure of the Madonna - perhaps resembling the Duchess Battista Sforza - was represented inside the space of a church for the first time. Some parts of this virtual architectural space are visible, especially those in the middle and upper sections, while the human characters conceal the limit with the floor. The assembly of saints and angels is in fact placed around the Madonna, who is much bigger in proportion. They form a sort of hemicycle, following the shape of the visible part of the church. Besides a small portion of the nave, it is possible to see the transept with its coffered arches as well as the choir, apparently covered by a coffered barrel vault and ending with 
Fig. 2 Madonna and Child with Saints (or Montefeltro Altarpiece, 1472-1474) by Piero della Francesca in its current location at the Pinacoteca di Brera (Milan). (Photo by the authors)

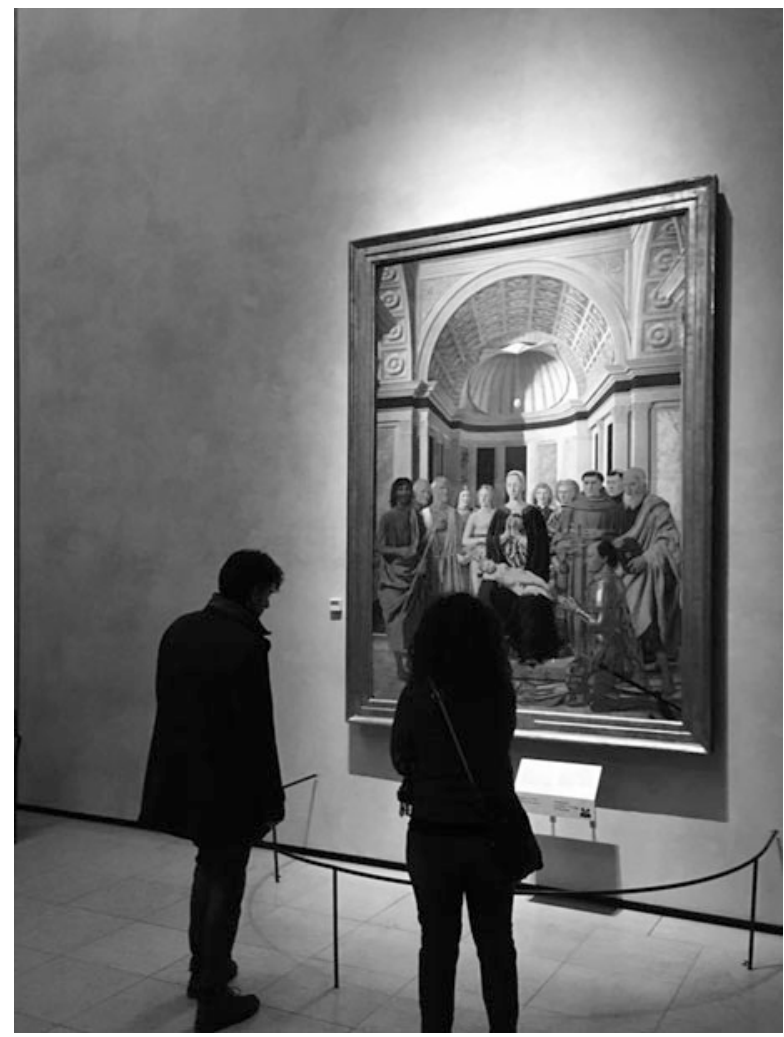

a semi-elliptical apse crowned by a cap, whose springer is a semicircle decorated with an upside-down marble shell, from which a golden chain hangs, holding an ostrich egg. The painting is virtually divided into two vertical sections: Piero was guided by the belief, expressed in his treatise, that the visible objects of the world achieve perfection in their geometric form (Meiss 1954). According to Ragghianti, the painting has probably undergone considerable cuts on all of its four sides (Meiss and Jones 1966), perhaps after an unspecified adaptation to the needs for a new arrangement in the San Bernardino church. The missing parts might have shown other portions of the painted church. However, the presumed extension of the painting, based on the golden ratio module, is now widely opposed by critics (Battisti 1974, p. 280) and particularly by Trevisani, who proves that the dimensions of the painting have not changed (Trevisani 1996).

Many scholars in the past have mistakenly determined the position of the characters painted in the altarpiece, some arranging them in front of the choir and others under the groin vault (Wilde 1929, p. 71). But the perspectival restitution here presented (Figs. 3 and 4) proves that the group is set in the nave, about $3 \mathrm{~m}$ from the transept and $11 \mathrm{~m}$ from the back wall of the apse. The ratio of the characters to the architecture seems to be solved by Piero by establishing the height 
Fig. 3 Perspectival restitution of the Madonna and Child with Saints by Piero della Francesca. The internal and external orientation of the perspectival image and the corresponding Mongian projections is obtained from the restitution.

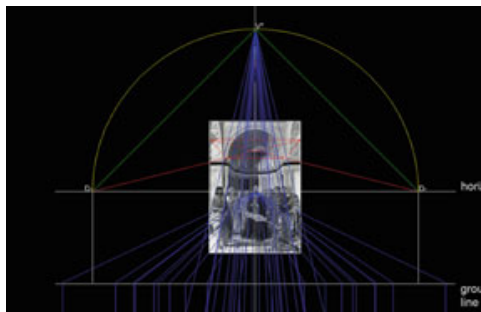
(Digital elaboration by D. Bortolato/Imago Rerum)

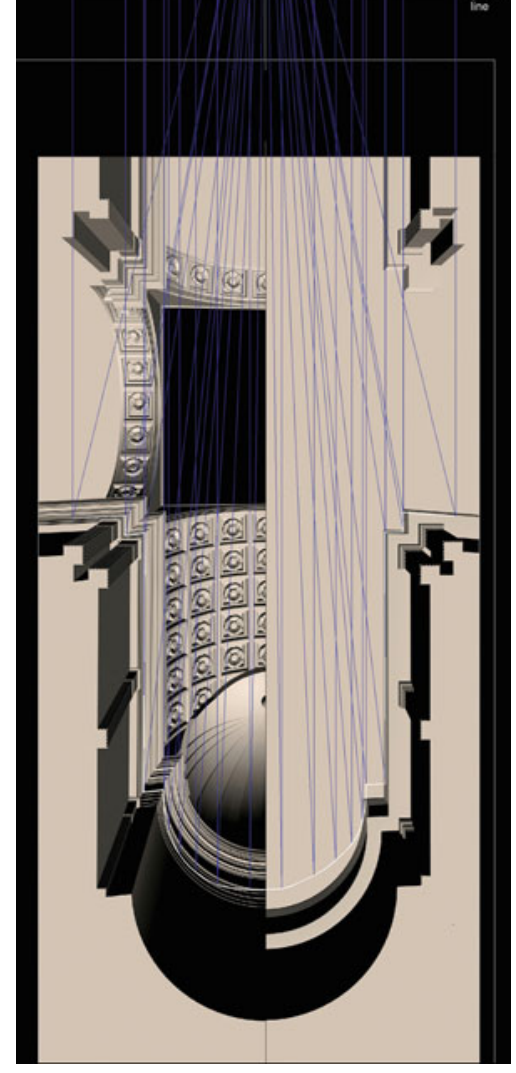

of the human figures - according to Meiss only $171.8 \mathrm{~cm}$, equal to three braccia fiorentine - as roughly a little more than half the height of the pillar, measured from the floor to the capital. The perceived weight of architecture, potentially heavier than the characters, is thus balanced by perspective, apparently reducing the distance between the characters and the background.

Piero carefully applied the laws of perspective to conceive and paint the interior, and it is possible that he had previously drawn plan and elevation, as Wittkower supposed about The Flagellation (Carter and Wittkower 1953). Piero must have deliberately determined the curious oblique position of the platform respect to the picture plane, since it is possible to see a perfectly horizontal stick between the 


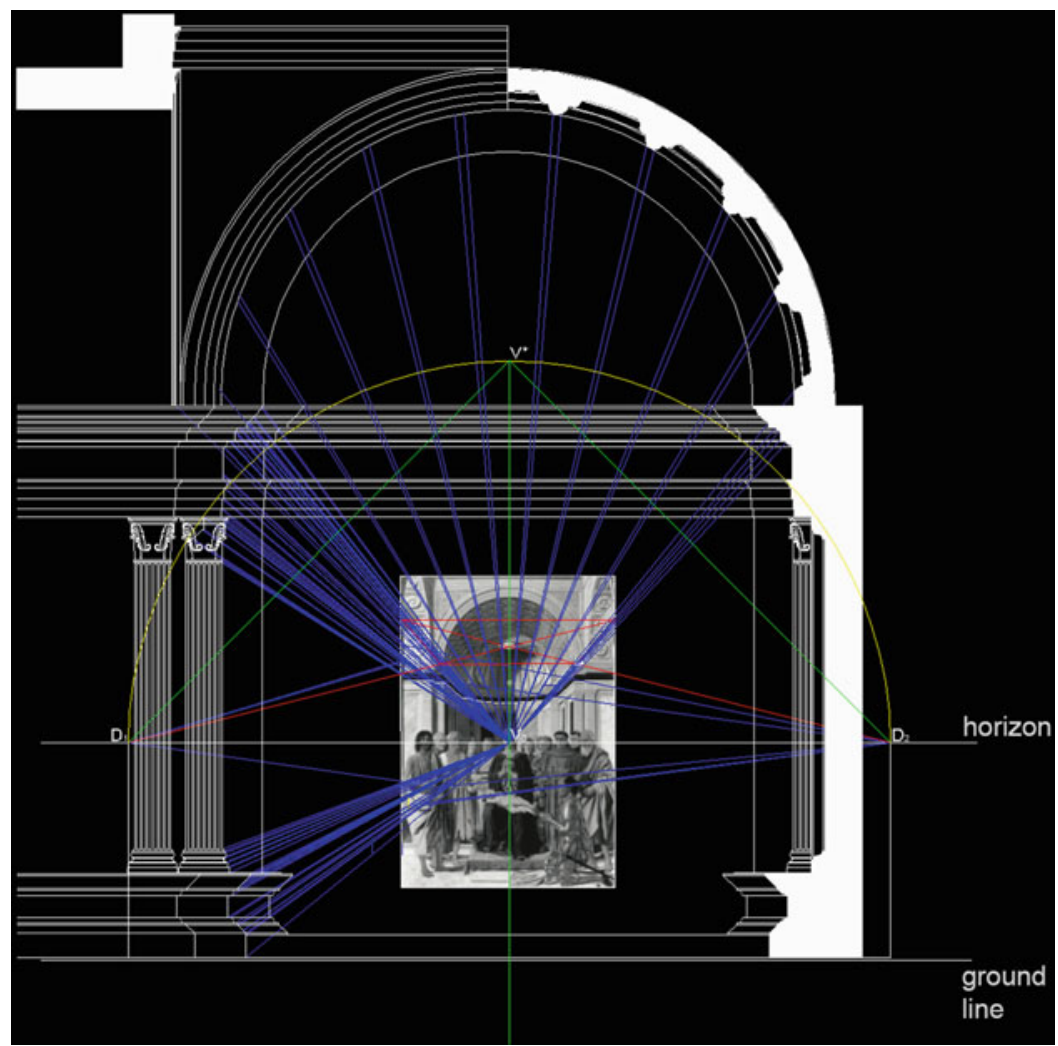

Fig. 4 Perspectival restitution of the Madonna and Child with Saints by Piero della Francesca. In evidence, the reconstruction of the painted architecture elevation. (Digital elaboration by D. Bortolato/Imago Rerum)

Duke's two metal mittens. All of the restitutions show the missing coincidence among the trace of the vertical plane passing through the vanishing point, the image of the golden chain from which the egg hangs and the axis of symmetry of the painting: this is clearly a choice of the painter.

As regards the internal orientation of the painting, the horizon is placed approximately at the height of the eyes of the painted characters: Piero follows closely Leon Battista Alberti's prescriptions. Moreover, the main distance, i.e., the distance of the observer from the picture plane, is equal to slightly less than twice the width of the painting.

While there are still doubts about the groin vault (Di Teodoro 1996, p. 30) and its distance from the possible windows of the transept and of the nave, the perspectival restitution (Figs. 5 and 6) confirms Piero's orthodox approach in addressing the problems of geometric representation of space. But the rendering of light and its visible effects on the painted scene is ambiguous: most of the light comes from 


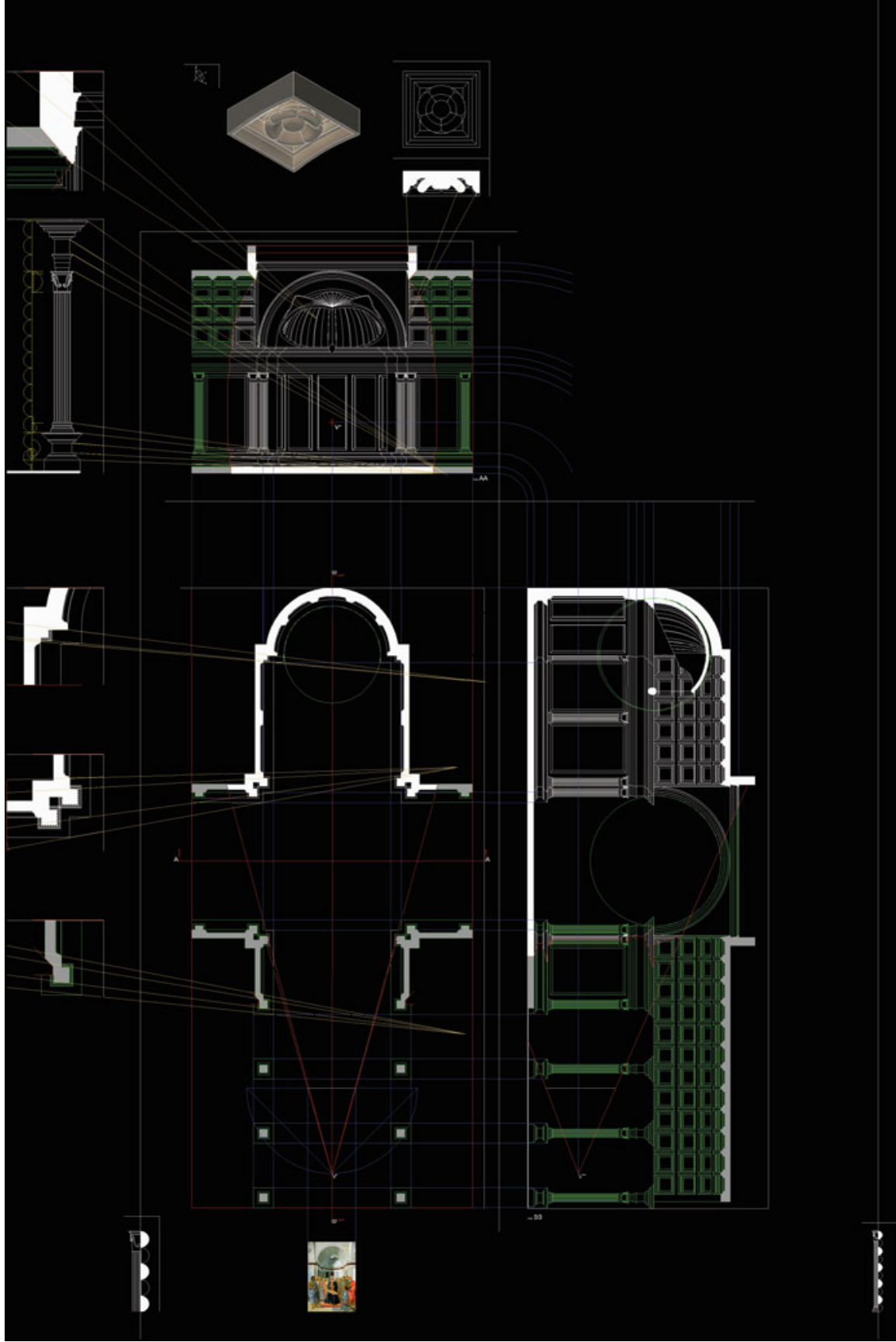

Fig. 5 Plan, sections, and details of the architecture represented in the Madonna and Child with Saints by Piero della Francesca. (Digital elaboration by D. Bortolato/Imago Rerum) 
Fig. 6 Axonometrical projections of the architecture represented in the Madonna and Child with Saints by Piero della Francesca. (Digital elaboration by D. Bortolato/Imago Rerum)

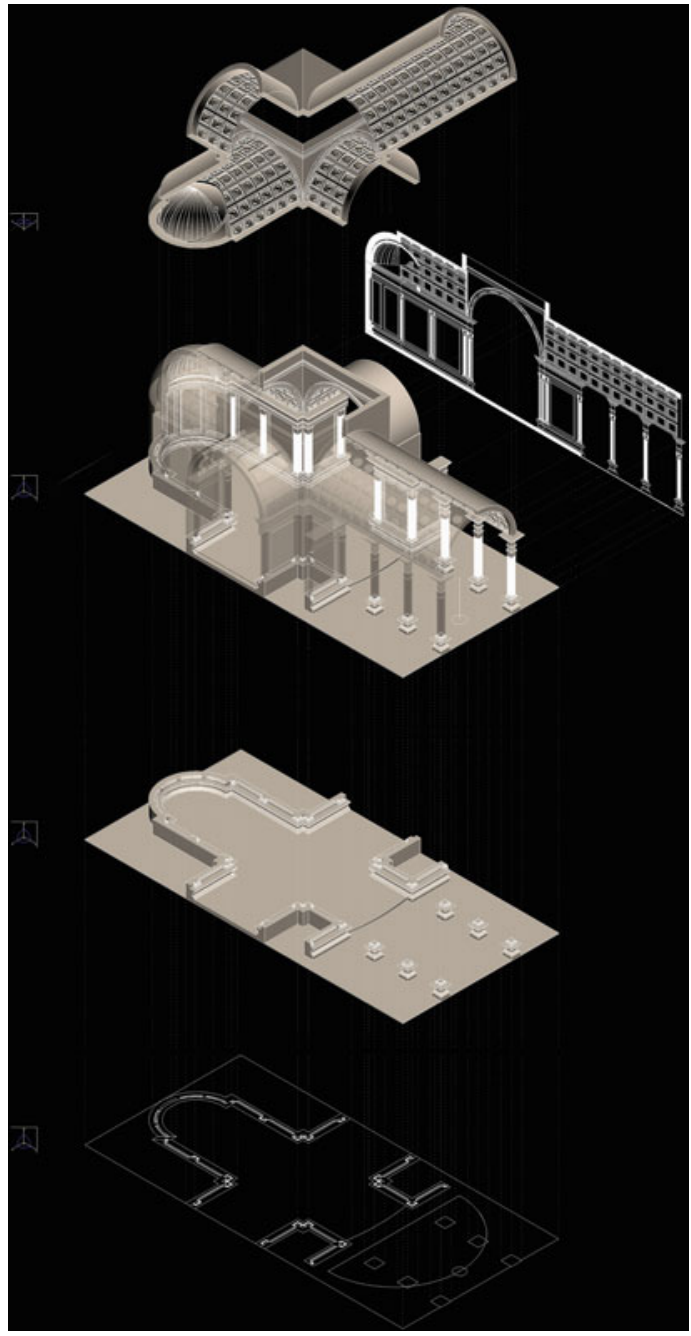

the left, maybe from an opening, probably arched, at the bottom of that side of the church, or from an artificial light whose shadow effects appear somewhat mitigated, besides the fact that they should follow the rules of conical projections. From this source, light spreads sharply over the entire transept, exalting the moldings of horizontal and vertical architectural elements that decorate the space; the same light also penetrates in the choir, touching the elliptical apse at the bottom of the scene (Fig. 7a-f).

However, looking at the exact position of the characters and observing the profiles of the shadows accurately traced on their faces, on their clothes, and on the architectural elements, there must be other windows open above the cross and along the walls of the nave: this is proved by the absence of shadows on the frame 
upon the central space and by the reflection of a window on the armor of duke Federico (Fig. 8a, b). Corrado Maltese identified the orientation of the reflection plane of the lower part of the shoulder armor, and consequently determined the origin of the rays of light as the center of a virtual opening on the left side of the nave (Maltese 1974, p. 287). By investigating the variation of light intensity on this piece of armor, Maltese affirms that this window ends at its bottom with a splayed parapet and has on its top a circular space, whose reflection could be produced by a lunette in the barrel vault that covers the nave. Since the early Christian period, "it is usual that the devotees turn eastwards (in orientes orantes, the alliteration is not accidental), so most of the churches are oriented like this" (Oursel 1986, p. 299). Therefore, if the apse is on the eastern side and the light source is the Sun, then the light that illuminates the Sacred Conversation should come from the North, which at Piero's latitude cannot be possible in reality. Maybe the painter deliberately chose a direction of light not according to a phenomenal event, but instead alluding to the presence of a radiation of celestial origin, an unnatural northern light that could subtract the scene to perceptual immanence. Any attempt to identify a real architectural space with its actual proper orientation must be excluded: probably Piero della Francesca employed human models exposed to an appropriately chosen natural light, according to a specific angle, and then used the obtained images and light effects for his pictorial purposes, setting the characters in a virtual architectural environment (Berenson 1950) artificially oriented as common churches. Piero reconciles two luminous universes, that of the characters and that of architecture, by choosing different angles of incidence for the luminous rays.

What was his purpose? His sensitivity towards light led him to match light and color with extraordinary results. Yet even in his treatise he has not left any graphical-geometrical scheme that could have helped his colleagues to deal with the problem of shadows within the theory of geometric perspective. Therefore, unless he had built a scale model of the painted environment, appropriately illuminated by a lamp or by sunlight or both, it is difficult to understand from which constructions Piero drew the various contours of shade and light upon the surfaces of this interior. The question makes sense, since if some of the shadows in the painting seem to respect the phenomenal and geometric rigor of the modern skiagraphia, others do not, which causes serious interpretative doubts to arise. The sore point is in the shadows projected in the choir and in the apse: here there are very complex problems, both for the geometry of the spaces and for the decorations. Moreover, the total absence of shadows generated by the suspended egg, like the seemingly inexplicable illumination that reaches the upper part of the shell, suggests a representative strategy. For this reason, once having carried out the perspectival restitution of the space represented in the painting, a simplification of these elements was obtained, focusing on the shadow problems concerning the pure forms of the painted architecture. This allowed to experimentally reproduce Piero's point of view by illuminating the abstract geometric plot.

The hypothesis according to which the author represented a space as deep as a traditional perspectival restitution would suggest could be verified, for example, by determining the vertical luminous plane grazing the outer edge of the left pillar 


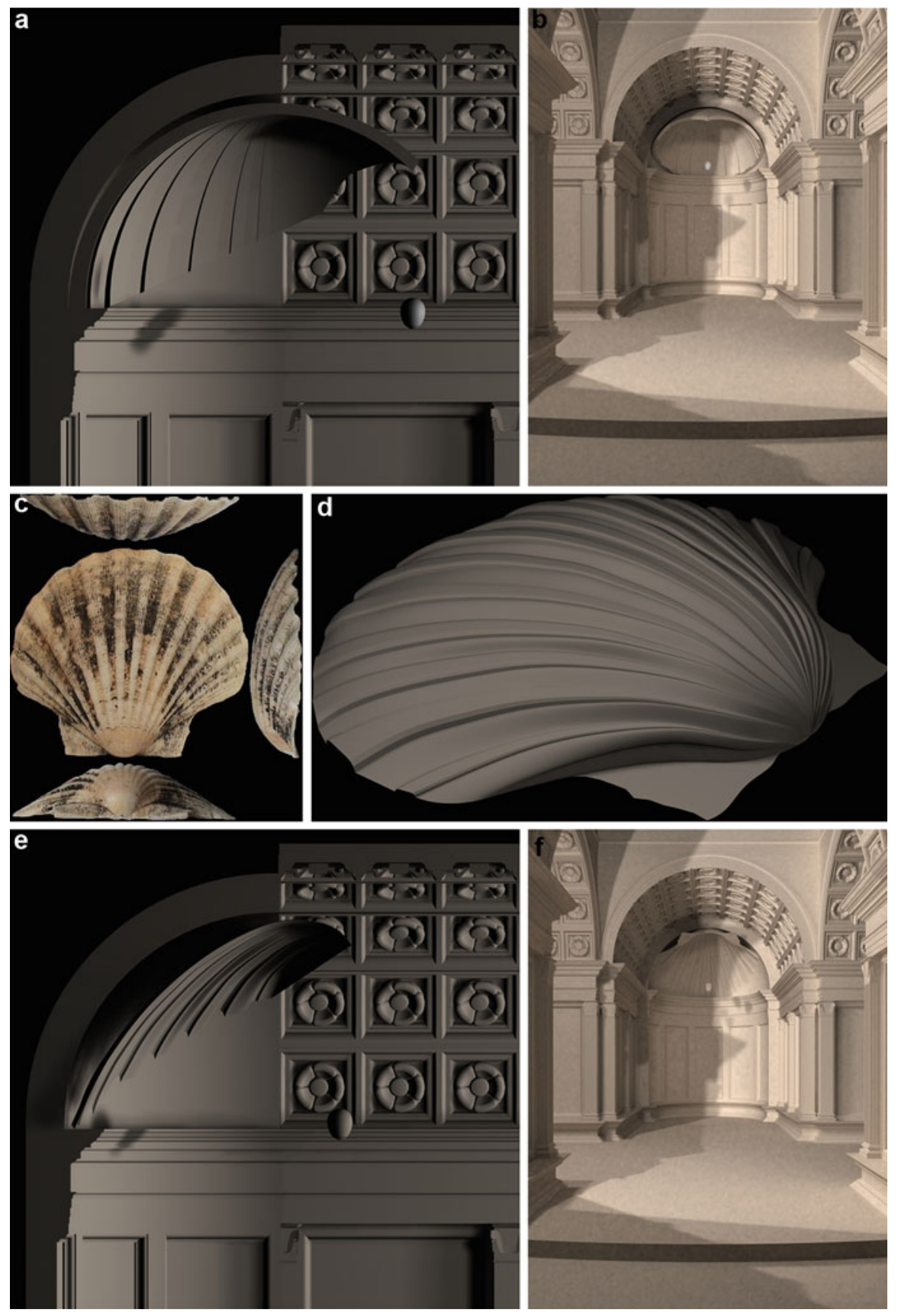

Fig. 7 (continued) 
of the presbytery, finding its trace on the floor and then the vanishing line: this planimetric trace, prolonged to the left part of the transept, shows that the transept itself is narrower than the choir. Besides, below the right arm of St. John the Baptist, there is, barely visible, the image of a windowsill, above and beyond which there might be a full-height window.

Looking for the light source, the major projective inconsistencies emerge: once having determined the circular contour of the shadow edge projected on the circular crown that lies in the vertical plane above the apse, it is possible to prove that this semicircle cannot belong to the shadow of the arch. In fact, these two semicircles should be congruent, and their centers should be aligned with the direction of the light source, still unknown at this stage. In particular, the shadow-curve does not follow the direction of propagation of the dominant light in the painting, which suggests the presence of another light source in front of the observer.

But there are even more ambiguities: the outline of that shadow should continues in the lower surface of the vault in an elliptical arc generated by the intersection of two cylinders: the lower vertical surface and the luminous cylinder. But there is no trace of this curve in Piero's painting, while at its place it appears clearly a straight line, a vertical section of the barrel vault above the choir, dividing direct light from shadow (Fig. 9).

There is at least the certainty that the light source is placed on the left side of the transept, suggesting that it is not in a proper point at a finite distance, since its hypothetical shadows, as results of a conical projection, would appear instead exaggerated when light would intersect the different surfaces of the choir and of the cross. But the sunlight coming from an opening on the left side of the transept, besides illuminating the choir, would also project a large shadow upon it, cast by the right jamb of this opening. This evidently contrasts with the painting, which draws a particular expressive strength specifically from the contrast between light and shadow in the choir.

Therefore, the hypothesis of sunlight as the only light source in the painting must be disregarded. Its effects are visible in the nave, but it is problematic to identify the inclination of the rays just from the information in the painting. The most reliable information is in the traces of the vertical luminous planes on the reference

Fig. 7 (a) Perspective reconstruction of the shell in the niche, whose configuration follows the one imagined by Piero della Francesca. (Digital elaboration by D. Bortolato/Imago Rerum). (b) Digital reconstruction, in orthogonal projection (section), of the shell painted by Piero della Francesca. The geometry of the shell is based on a hemisphere with fifteen ribs and an oblique cut of 25 degrees. (Digital elaboration by D. Bortolato/Imago Rerum). (c) Orthogonal projections of the shell (Chlamys Flexuosa) which inspired Piero della Francesca to paint the shell in the Madonna and Child with Saints. (Digital reconstruction by D. Bortolato/Imago Rerum). (d) Digital model (axonometrical view) of Chlamys Flexuosa. (Digital elaboration by D. Bortolato/Imago Rerum). (e) Perspective reconstruction of the Chlamys Flexuosa in the niche. (Digital elaboration by D. Bortolato/Imago Rerum). (f) Digital reconstruction, in orthogonal projection (section), of Chlamys Flexuosa in the niche. The drawing shows the difficult adaptation of the shell shape to the calotte. (Digital elaboration by D. Bortolato/Imago Rerum) 

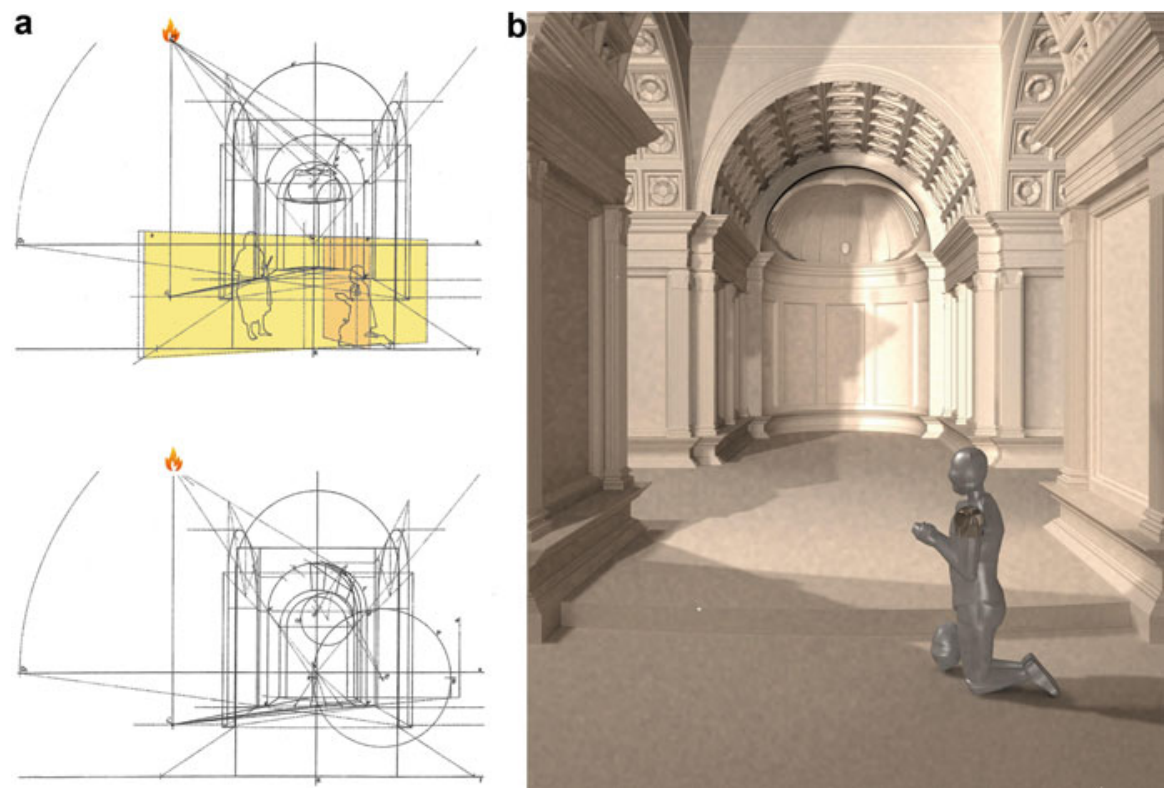

Fig. 8 (a) Skiagraphic analysis of the painted shadows in the Madonna and Child with Saints, in the hypothesis of a point source and a series of windows in the nave. (Perspective drawing by Agostino De Rosa). (b) The digital reconstruction of the armor worn by the Duke of Montefeltro suggests that the light reflected from its shoulder comes from the entrance door of the church. (Digital elaboration by D. Bortolato/Imago Rerum)

horizontal plane. It is possible to find the shadows, in the architecture imagined by Piero, by gradually shifting the inclination of the sun rays entering through the large arched openings described by Maltese. This inclination is comprised between two positions, both detectable by observing the painting: the sun cannot be lower than the springer of the vaults, as the details of the shadows on the faces of the painted characters reveals; nor can it come from the zenith, because in similar circumstances the right side of the nave should appear shaded as well.

Which source could illuminate at the same time the transept, the nave, and the apse like it happens in the painting? Even if with a few contradictions, the only possible answer is that a candle projected its light from the left side of the transept. Its planimetric position can be geometrically determined with sufficient precision (De Rosa 1993), while its height should be much above the left arch of the transept, within the structure of the barrel vault. Let's consider possible the absurd placement of the light source in order to study its effects only in the choir and the apse, to test the reliability of Piero della Francesca's shadows. Investigating only the choir, without considering for the moment the apse, the shadow edge appears completely different from that of the painting: the shadow cast from the frontal arch upon the circular background is very close to the springer plane of the barrel vault and is therefore lower than the shadow in the painting. The same happens with the shadow 


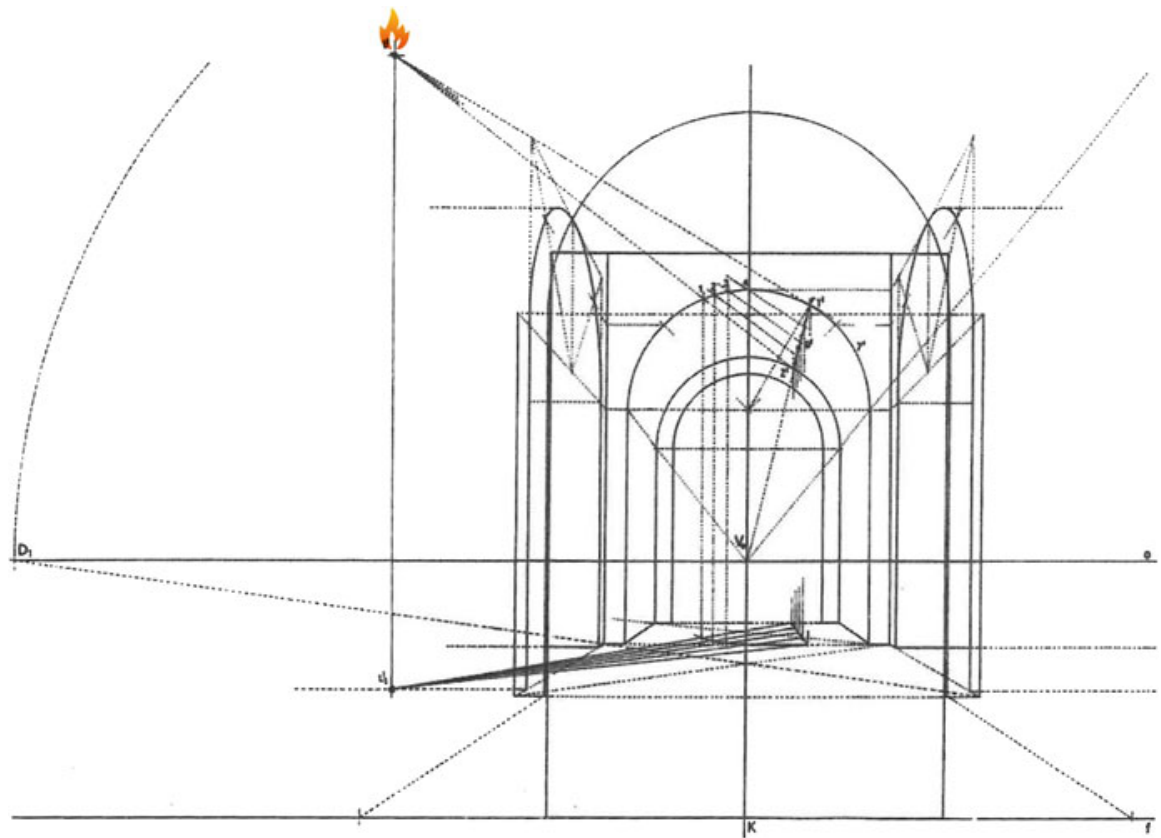

Fig. 9 Determination of the shadows cast in the choir of the architecture depicted by Piero della Francesca. (Perspective drawing by Agostino De Rosa)

projected by the arch of the choir on the vault's intrados, whose edge is an elliptic arc and not a straight line. The straight line on the cylinder, if interpreted as a correct shadow, would represent the projection upon the barrel vault of an ambiguous curved surface.

It seems impossible again to analyze the painting skiagraphically; it is possible instead to try with eidomatics, which is to say by building a real scale model (1:20, Fig. 10a-c) and a digital clone of the architecture painted by Piero, and then setting the position of the light source according to the shape of the transept, where Piero imagined it. During this experiment, a software simulates the phenomenal behavior of light. In the first sequence of perspectival images here presented, the eye of the observer (the virtual camera) is placed exactly where Piero set the point of view. They show that if the space is illuminated by the light sources placed in the various positions hypothesized, the effect is still very different from what the painting displays: the shadow edge cast by the front arch of the presbytery is not a straight vertical line as in the painting but appears instead as an elliptical arc, as it was demonstrated before. This curve matches the circular arc which is the projected shadow edge of the presbytery's front semicircle, on the arch above the cylindrical niche. In the half spherical cap at the top of this space, the shadow edge continues uninterrupted, drawing an elliptic arc in the cap and a quartic curve on the cylindrical body of the niche, tangent to the projected shadow edge of the left border (Fig. 11). 

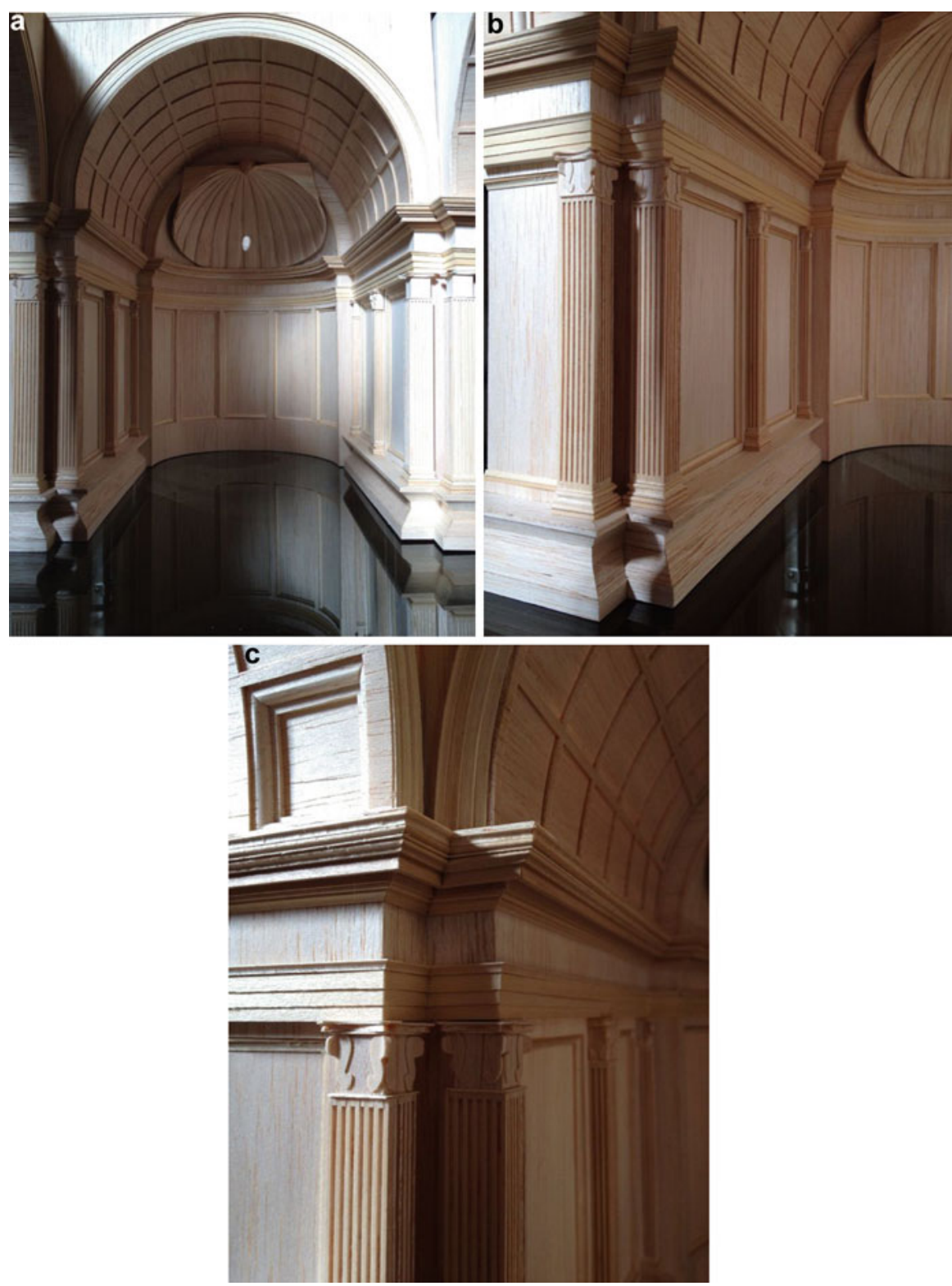

Fig. 10 (a-c) Wooden model of the architecture painted by Piero della Francesca. (Model by D. Bortolato/Imago Rerum)

In the model visible in the figures, the cross is purposely left without roof: in the painting, this is suggested by the absence of shadows on three sides of the upper level. It must also be noticed that the shadows on the bodies of the saints and of 
Fig. 11 Synoptic table where cast shadows are analyzed and compared in the painting, in the digital model and in the wooden model. Details of cast shadows in the barrel vault and in the stringcourse cornices on the right; cast shadows of the suspended egg and projected shadows of the trabeation on the right. (Photos and digital elaborations by $\mathrm{D}$. Bortolato/Imago Rerum)

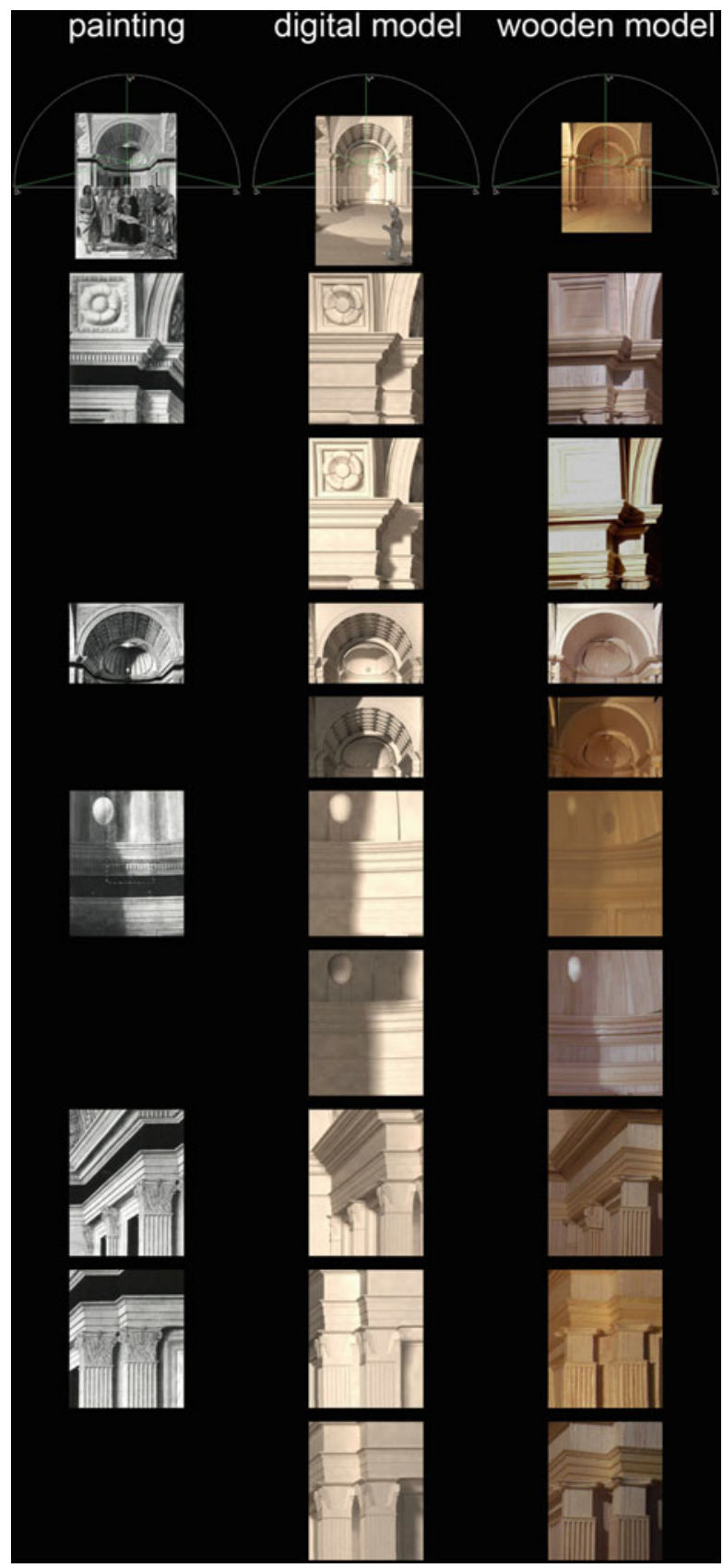

the Virgin Mary suggest that there might be other windows in the side walls of the nave, as well as in the barrel vault. The walls and the vault cannot be illuminated by candles because the cast shadows would be very big when projected on the walls. It 

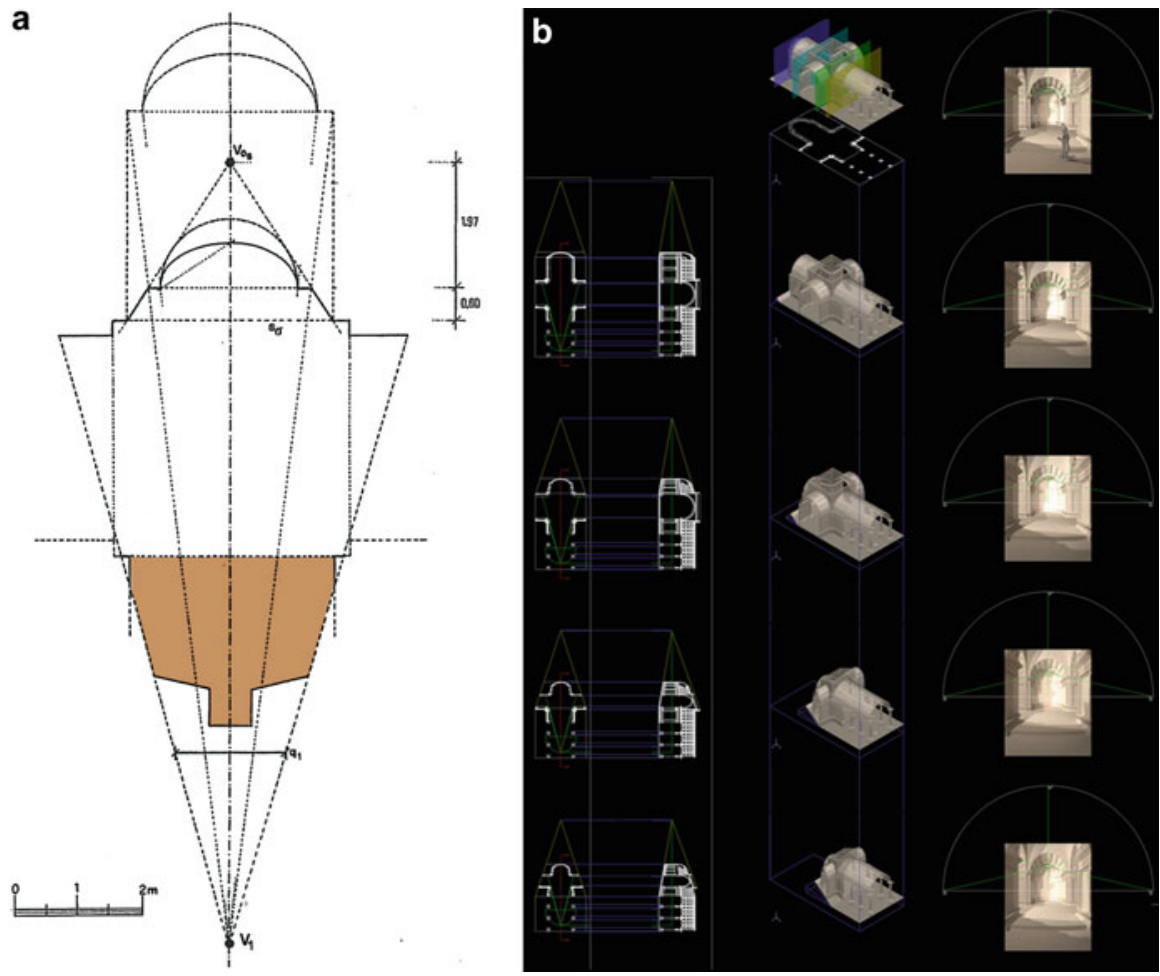

Fig. 12 (a) First interpretative hypothesis of the Madonna and Child with Saints by Piero della Francesca: the chorus in solid perspective. (Drawing by Agostino De Rosa). (b) Several hypotheses of scenographic compression (perspective acceleration) of the architecture painted by Piero della Francesca. The skiagraphic tests on the digital model prove their inconsistency. (Digital elaboration by D. Bortolato/Imago Rerum)

is necessary to consider another hypothesis proposed by some scholars (Maltese 1974) to justify the skiagraphic inconsistencies of the painting: the possibility that the space of the choir and apse had been imagined by Piero as an illusory representation of an architecture built according to the rules of solid perspective, or relief perspective: a perspectival system where the improper entities - i.e., points and lines at an infinite distance - of the projection plane become physical entities located in real space, at a finite distance. Once having established the depth of the illusory space to be represented, as well as the position of the observer, geometry allows to build any element of this virtual space, keeping in mind that both the improper line of the ground horizontal plane and the improper point of the lines perpendicular to the picture plane become, respectively, a line and a point, with a "finite" spatial position (Fig. 12a, b).

If solid perspective turns into a designed scenic space, relief perspective has stronger ties with the plastic arts because it consists in a sculptural technique 
Fig. 13 Guidobaldo Del Monte, Perspectivae Libri Sex, Pesaro 1600

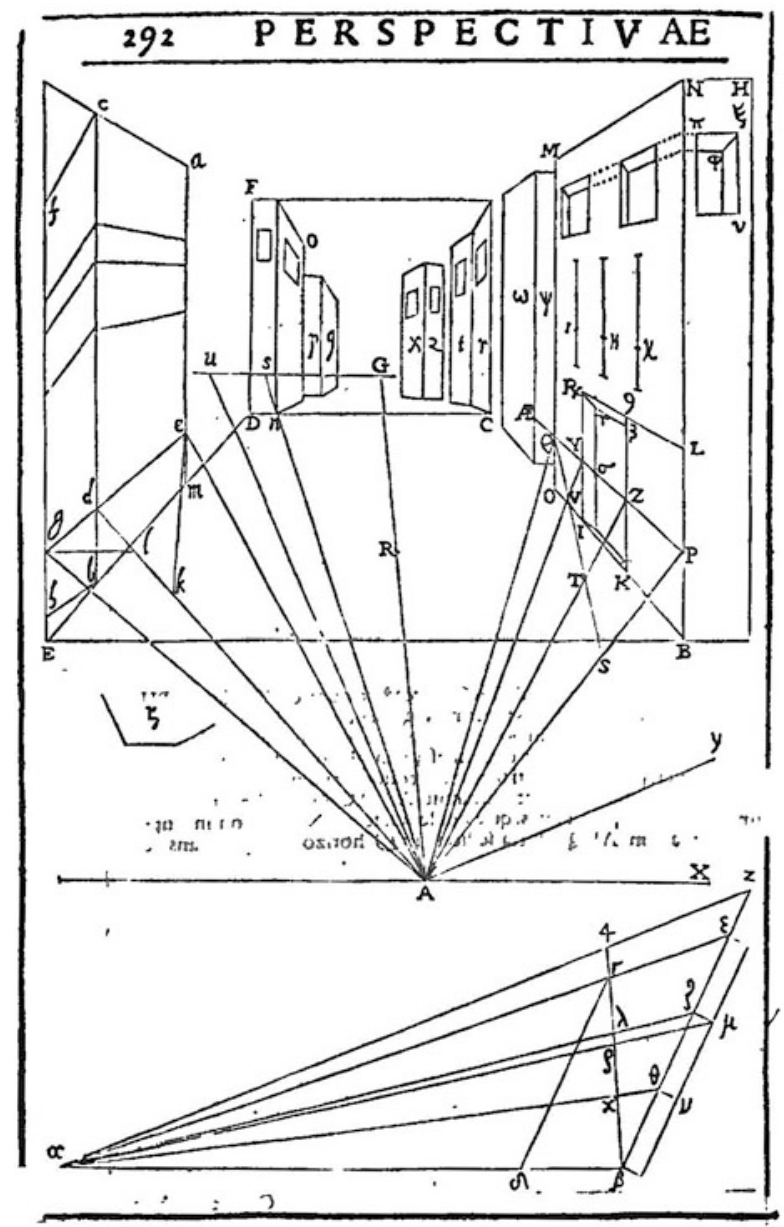

(the same used in the bas- and high reliefs) aimed at perceptually increasing a small spatial depth, for example of a decorative panel. A brilliant proof of this evocative sculptural technique is provided by the huge relief perspective by Donato Bramante at the church of St. Maria presso San Satiro (Milan, 1482-1486), where he impresses a remarkable perspectival acceleration to all of the architectural elements of a virtual choir, compressed into a space $1.2 \mathrm{~m}$ deep. The illusory effect is so convincing that the observer, standing at a determined point in the nave, perceives the almost perfect image of a deep three-aisle choir. It is unlikely that Piero knew how to build a solid perspective, even more because in this case it would have been accelerated: he should had been able first to imagine and then to represent a space where floor, lateral walls, and roof would be deformed to create the illusion of a big depth. 
There is no treatise dealing with this problem before Guidobaldo del Monte published his Perspectivae Libri Sex (Fig. 13) in 1600. Piero could have drawn only from the incomplete stagecraft rules of his time to design a "fake architecture" as complex as the one painted in his altarpiece. In fact, the accelerated space would have needed - in addition to the lifting of the floor and the grade and deformation of the lateral walls of the choir - a transformation of the barrel vault, which would have turned from a semi-cylinder into a semi-truncated cone. Furthermore, the apse, a niche with a semi-elliptical plan, would have turned into a much narrower and shortened space, whose upper part would have been a quarter of an ellipsoid. All of the aforementioned deformations would have disappeared if observed from a precise point of view, providing the illusion of a much deeper choir. If Piero had been aware of the perfect coincidence between real perspective image and virtual image, that is between illusory space and deformed space, he would not have needed preparatory drawings, because only light (and the consequent shadows) would have made appear the difference between the two spaces. It is important to understand the complexity of the theoretical problem that Piero faced: he was perhaps able to approximately imagine a scenic space, and probably to build it in scale, but not to control its shadows by means of geometry nor to correct them where necessary. According to this theory, it would be possible to hypothesize that the sacred assembly had been positioned to hide the areas where the luminous inconsistency would have been maximum: the floor. However, even this hypothesis leaves many of the problems of skiagraphic consistency unsolved, arousing the irresolvable question of such a transgressive choice made by Piero della Francesca at the top of his career (Fig. 14).

Another hypothesis could consider perspective acceleration techniques not only for the choir, but also for the cross and transept: the plan $s$ of the "proscenium" should then be moved at the center of the cross, and in a depth of about $60 \mathrm{~cm}$ there should be a space much deeper than the choir alone. Moreover, the presence of the big arch $m$, limiting the perception of the transept in the upper section of the paining, would allow the virtual arches on the transept to be not completely built, but instead interrupted at their visible limit. A similar stage machine, simulating in small dimensions a space circa $6 \mathrm{~m}$ wide and $7 \mathrm{~m}$ deep, could have been made by Piero as a background independent from the characters on the foreground. In other words, it would not be a proper architectural decoration (a bas-relief representing the choir, as in Bramante) that aims at breaking through an existing space (the cross and the nave of the church), but an "empty scenario [...] telescoped and related with the space available in his [Piero's] atelier and to be filled in many ways and for many purposes" (Maltese 1974). Piero could have built a set, in front of which he could have staged the sacred assembly, working in his atelier in San Sepolcro with the light coming from the windows. This hypothesis does not however dispel the inconsistencies in the distribution of light and shadows in the altarpiece; on the other hand, the room that was probably Piero's studio has today two windows facing North, which would not allow direct light but only a diffused illumination, diminishing the contrasts between illuminated and shaded areas, while exalting instead the perception of the sfumato. By illuminating the replicas of this set, it is possible to verify that with an artificial light the shadows within the choir have 

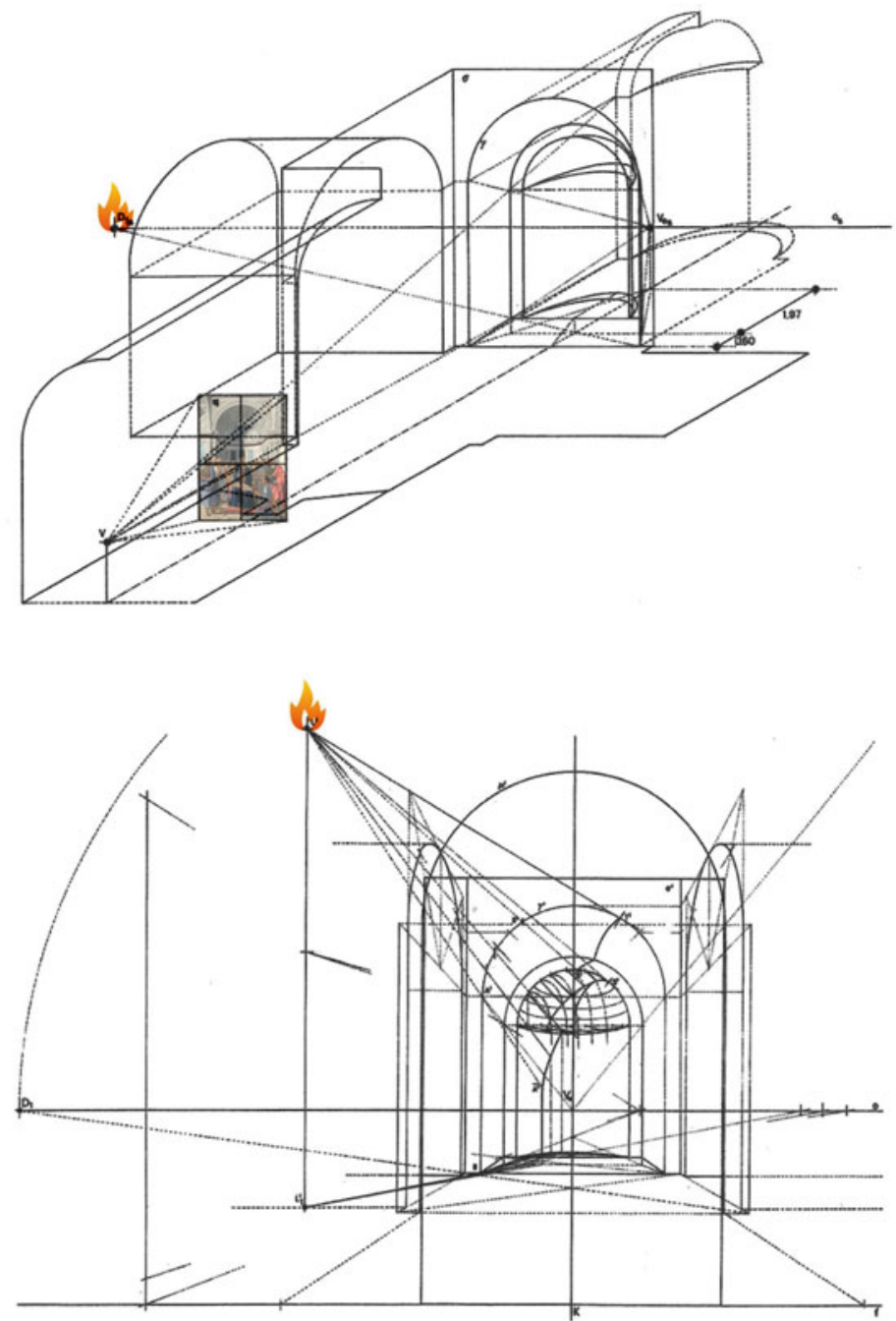

Fig. 14 First interpretative hypothesis of the Madonna and Child with Saints by Piero della Francesca: the chorus in solid perspective. In the axonometric image, the compression of the choir and the position of the painter/observer. In the perspective image, skiagraphic test for the chorus illuminated by a point source. (Drawing by Agostino De Rosa)

once again very different shapes from those represented by the artist (Fig. 15a, b). Even in the hypothesis that the model was exposed to sunlight, the incongruence between the results obtained and those visible in the painting is evident (Fig. 16).

The impressions emerging from this examination of the Sacra Conversazione are clearly contradictory: on the one hand it is reasonable to disregard the hypothesis of an executive and theoretical error by Piero or by his assistants, because of the 

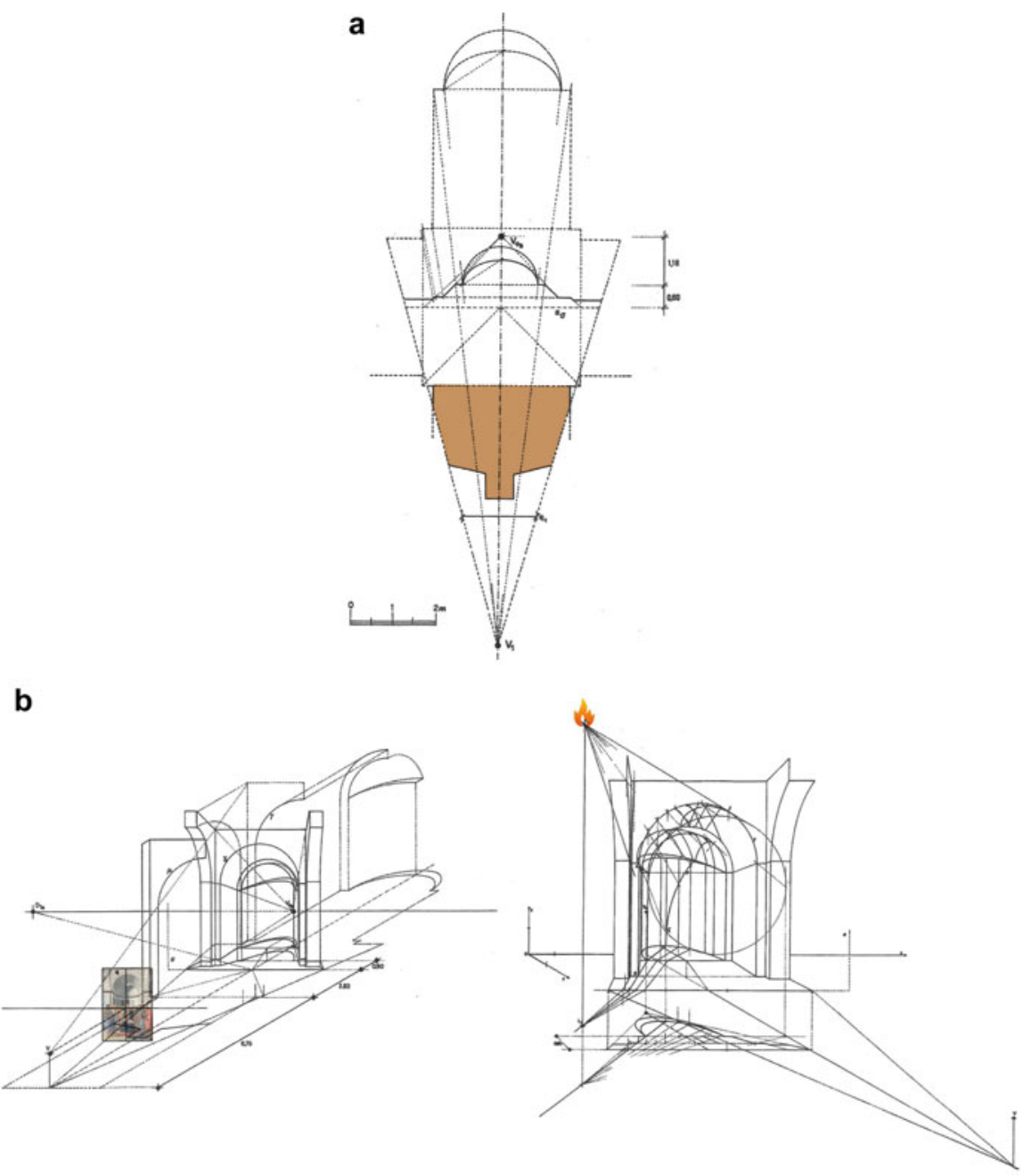

Fig. 15 (a) Final interpretative hypothesis of the Madonna and Child with Saints by Piero della Francesca: the chorus and the transept in solid perspective. (Drawing by Agostino De Rosa). (b) Final interpretative hypothesis of Madonna and Child with Saints by Piero della Francesca: the chorus and the transept in solid perspective. In the axonometric image, the compression of the space between chorus and transept, and the position of the painter/observer. In the perspective image, skiagraphic test on the accelerated chorus and the transept illuminated by a point source. (Drawing by the Agostino De Rosa)

extreme awareness shown in other similar problems of light and shadow; on the other hand, there is coherence in every single shadow, when examined separately from the others. Each segment of each shadow edge could be generated by a suitable light source, even by the Sun in different positions. Even the unlikely shadow edge in the intrados of the barrel vault of the choir could be correct, if we consider that it 


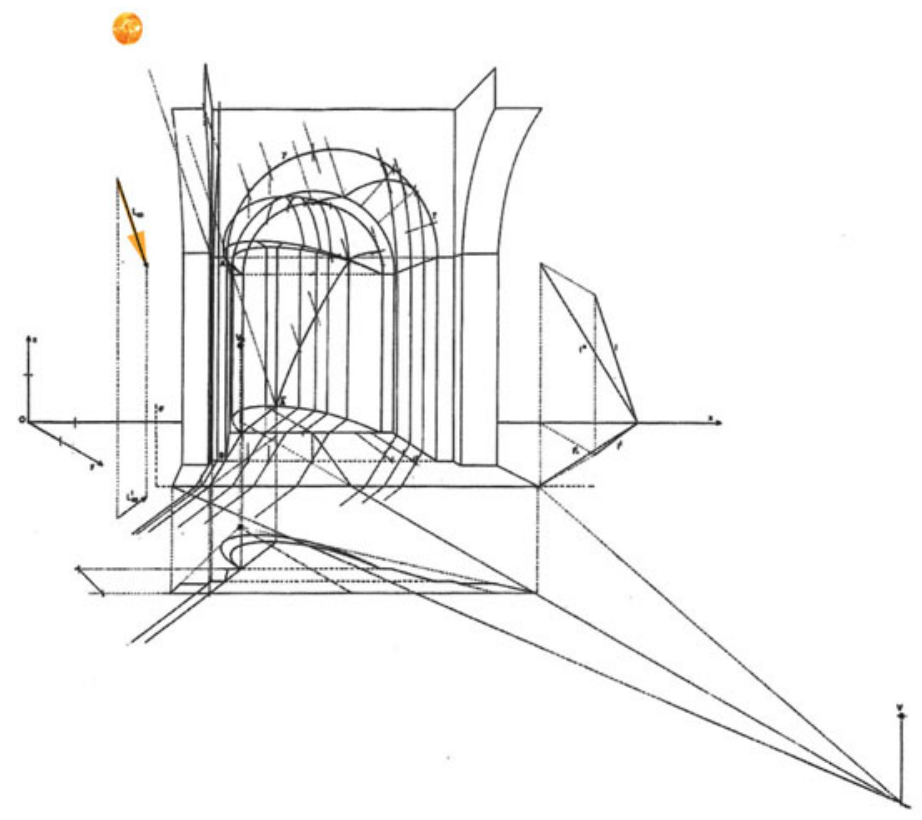

Fig. 16 Perspective image with the skiagraphic test on the accelerated chorus and the transept illuminated by sunrays. (Drawing by Agostino De Rosa)

could be an elliptic arc - as it should be, according to the theory of shadows - with a very small curvature, obtained by projecting the semi-circle $g$ from a proper light source.

This hypothesis is risky, but it is possible anyway to imagine Piero experimenting in his last work what had never been seen before: through the continuous drifting of the painted shadows, he might have wanted to document the passing of time, the inexorable passing of hours. The space-time diagram hidden in the painting would then, in a symbolic and allegoric key, represent an earthly counterpart to the shining assembly of saints on the foreground, balancing the sense of calm perfection that can be experienced when looking at the face of the Madonna (Fig. 17). Through the perfect perspectival construction, the painted architecture would provide a pure geometric scenario in which to measure the temporal distance of the earthly events from God. The role of shadows would be a role of mediation between the two dimensions.

Only an explanation that escapes phenomenal rigor would let us think about Piero della Francesca as a painter not only of light, but also through light. Piero would be the artist who, by means of the art of painting, could bend for narrative and metaphysical purposes the most complex categories of human experience: space and time. 


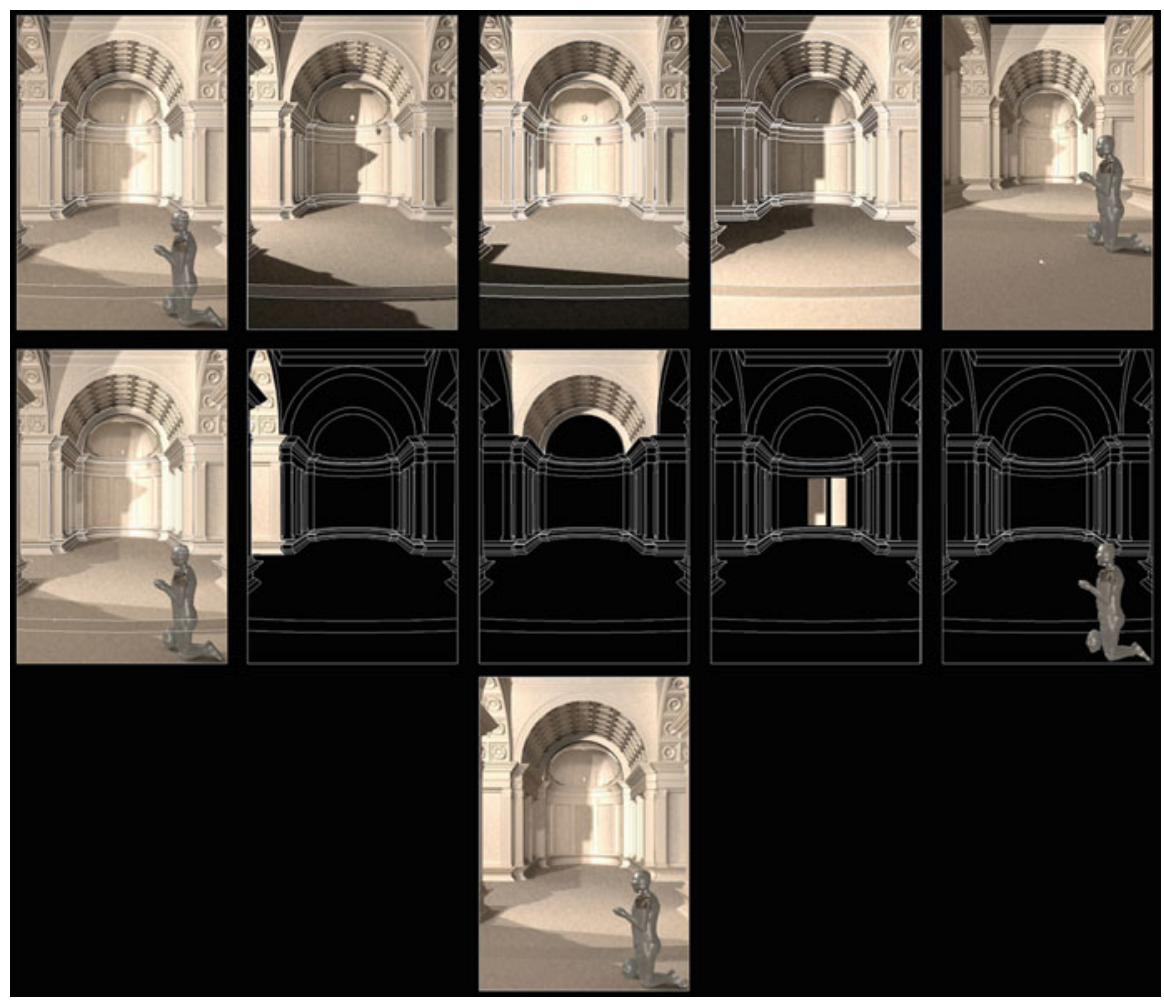

Fig. 17 Synoptic table of all the shadow effects studied in the painting. (Digital elaboration by D. Bortolato/Imago Rerum)

\section{James Turrell's Darkness}

The Dark Spaces series of site-specific installations is a not well known, but nonetheless important part of the production of the Californian artist James Turrell. Darkness plays a fundamental role in many of his works, e.g., in those classified as Projections (Fig. 18a, b), Wedgeworks (Fig. 19), Space Division Constructions (Fig. 20), Skyspaces (Fig. 21), and even in the plans for the Irish Sky Garden (Fig. 22) and in the Roden Crater Project (Figs. 23 and 24) (for a classification of his body of work and detailed descriptions of each type, e.g., Torres 2004; De Rosa 2007). The genealogy of the Dark Spaces can be traced back to the Mendota Stoppages (De Rosa 2007, p. 34), a sort of visual score for the rooms of a building which is tuned, like an orchestra, to the polyphony of the luminous events both generated inside and coming from the outside at the Mendota Hotel in Ocean Park, California. In the Dark Spaces, blackness apparently even overcomes the rigorous geometric component typical of Turrell's modus operandi, where mathematic and geometry are involved in tuning the architectural ratio on which partly depends the 

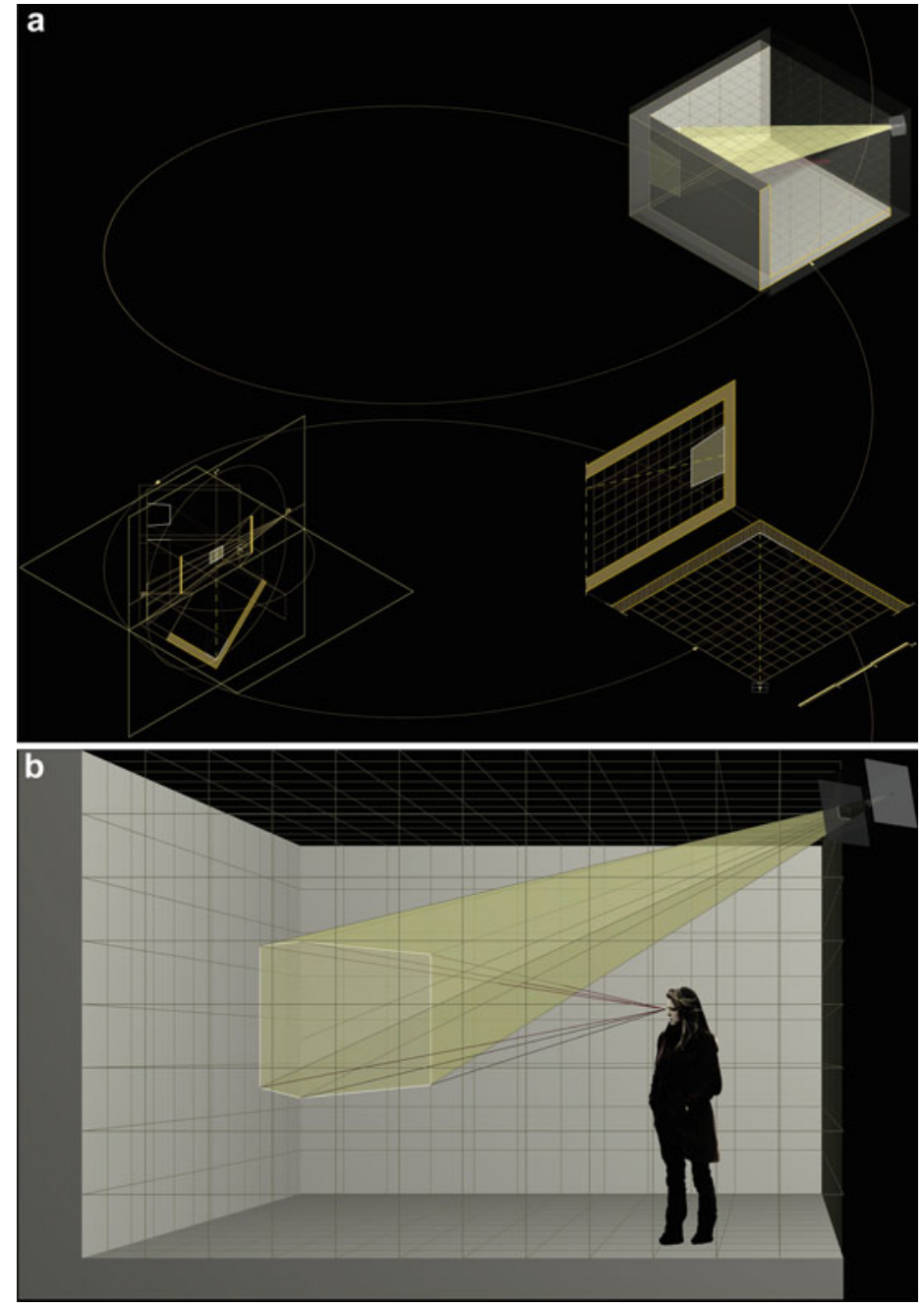

Fig. 18 (a, b) James Turrell, Afrum-proto, 1966. (Digital image by Francesco Bergamo, 2005)

success of the visual illusion, similarly to how a good concert hall or an acoustic musical instrument depends on their shapes and materials.

The first work of the Dark Spaces series is titled Pleaides, dates back to 1982 and owes its name to the fact that, in order to count the stars of the Pleiades constellation without the aid of dioptric devices, it is convenient to look sideways rather than staring at it directly. The artist wants us to become aware of the activation of our peripheral vision, what in some animals is usually referred to as "night vision" (cfr. Palmer 1999, pp. 28-35) and pertains to the rod cells in the retina, arranged around the cones from which day vision depends. Peripheral vision, the human mode of 


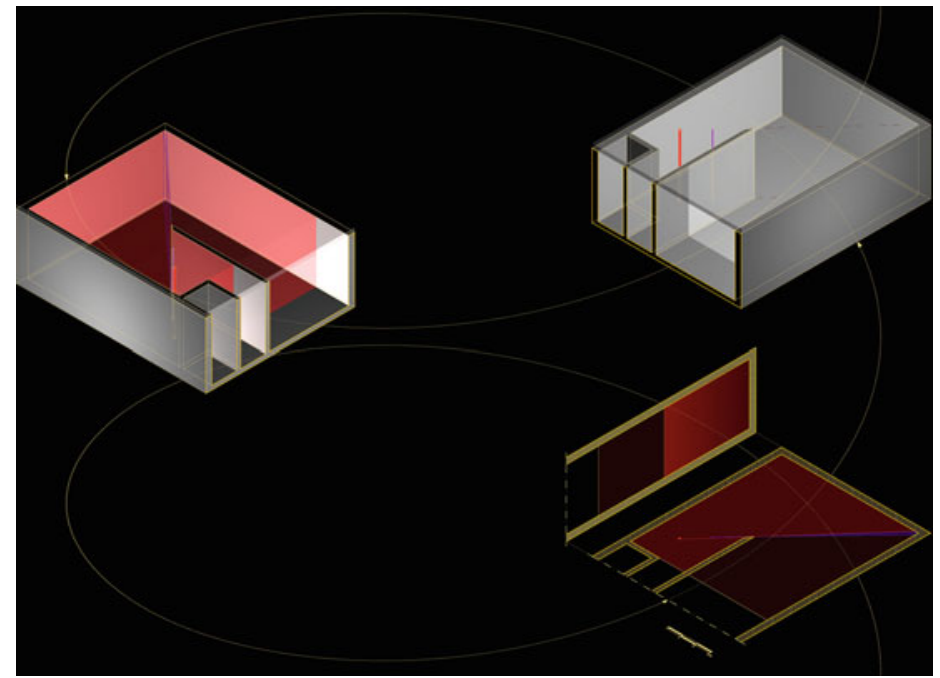

Fig. 19 James Turrell, Wedgework IV, 1974. (Digital image by Francesco Bergamo, 2005)

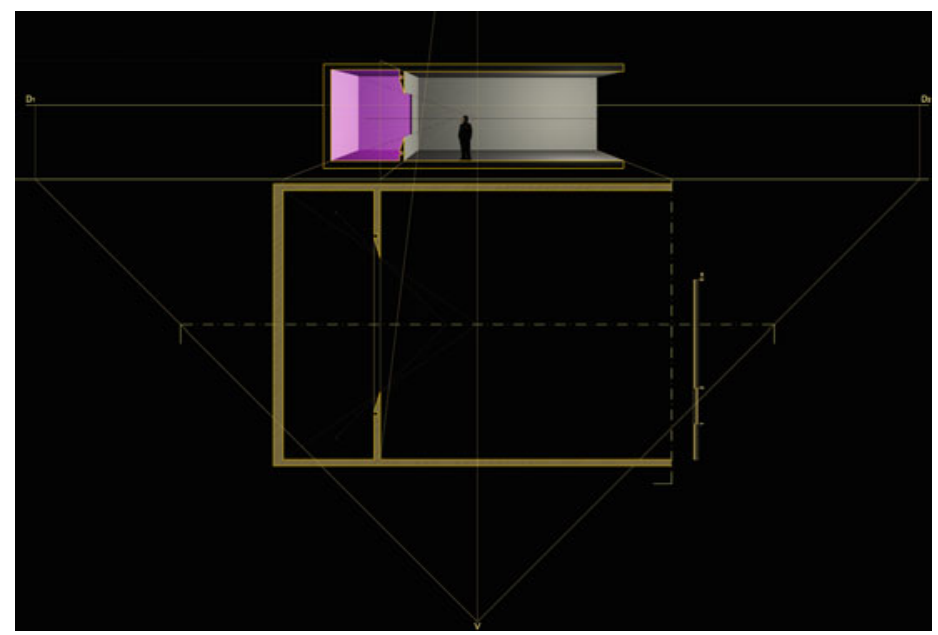

Fig. 20 James Turrell, Trace Elements, 1993. (Digital image by Francesco Bergamo, 2005)

seeing when the quantity of light is scarce, is characterized by blurred outlines and the lack of detailed color recognition.

Turrell's interest towards darkness in these spaces should not surprise those who are already familiar with his works: he is often considered a "light and space artist" (Adcock 1990; Butterfield 1993), but light needs darkness in order to produce sensations and organize perceptions, as much as sound needs silence in order to emerge and be perceived. Darkness and silence are a sort of tabula rasa upon which 


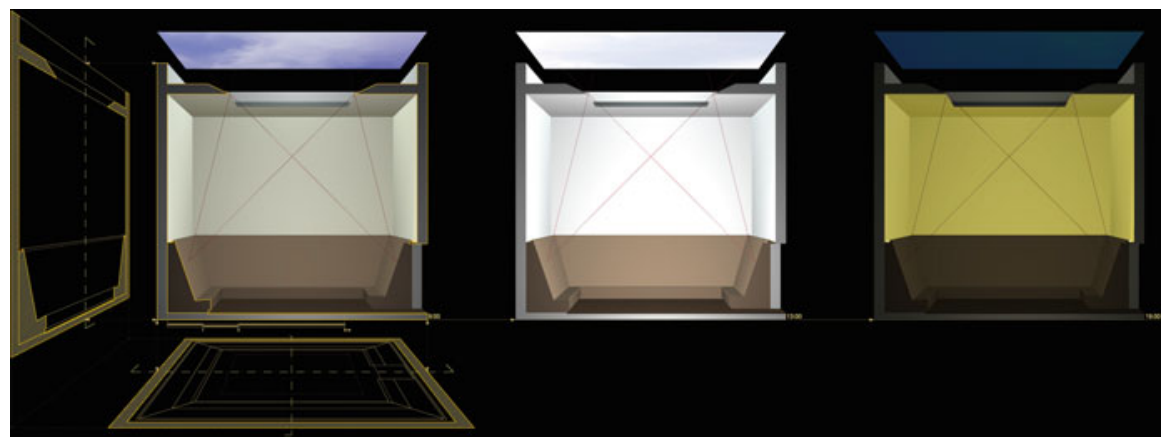

Fig. 21 James Turrell, Air Mass, 1993. (Digital image by Francesco Bergamo, 2005)

shapes can be defined and ordered by artists and then be recognized by spectators. The sound artist and philosopher François Bonnet explains clearly how "the sensible world $[\ldots]$ becomes assimilated into this world on the sole condition that it is clarified - that is to say, integrated by a protocol of representation. Sensation alone, mute and fleeting, is never fixed anywhere. It is fuel for the perceptual imagination that will re-present it as clear and enduring. Qualified perception thus already belongs to the order of representation" (Bonnet 2017, pp. 10-11) and in Turrell, as in Piero della Francesca, this sensible order is always geometrical.

Turrell's debt towards the silent musical composition $4^{\prime} 33^{\prime \prime}$ by the American composer and artist John Cage (1912-1992) is evident and explicit, with the important difference that Turrell stages very specific conditions in his works, while Cage was interested in every possible sound configuration. It is relevant that in order to understand the famous silent piece by Cage (Gann 2010), which can be also considered as a Zen exercise to develop awareness of what happens and can be heard in silence, it is impossible to ignore the influence of Robert Rauschenberg's White Paintings, a sort of tabula rasa animated by ever changing shades and shadows, and the experience of the composer in an anechoic chamber, during which he realized that absolute silence does not exist: once having eliminated the acoustic stimuli of the ecological, external everyday environment, it is still possible to listen to the sounds of the cardio-circulatory system and maybe even those of the nervous system, if Cage was right. In a similar way, even in total darkness humans always see something, both on the level of perception and on that of sensation. The presence of idioretinal (due to the intrinsic electrical excitation of the retina) images cannot be eliminated, and when they manage to capture a human's attention, her senses and her brain are activated and begin struggling in the vain attempt to reconstruct a coherent spatial reference system. Blind and partially sighted people obviously use other sensory stimuli to perceive spatial configurations and move in them. But since Western culture became a visual and image-based culture, starting from the Renaissance, most of humans today are not aware of how they listen as much as of how they see. Most of us would not believe that it is possible to go biking without seeing, but some blind people, opportunely trained, can do it, orienting themselves 


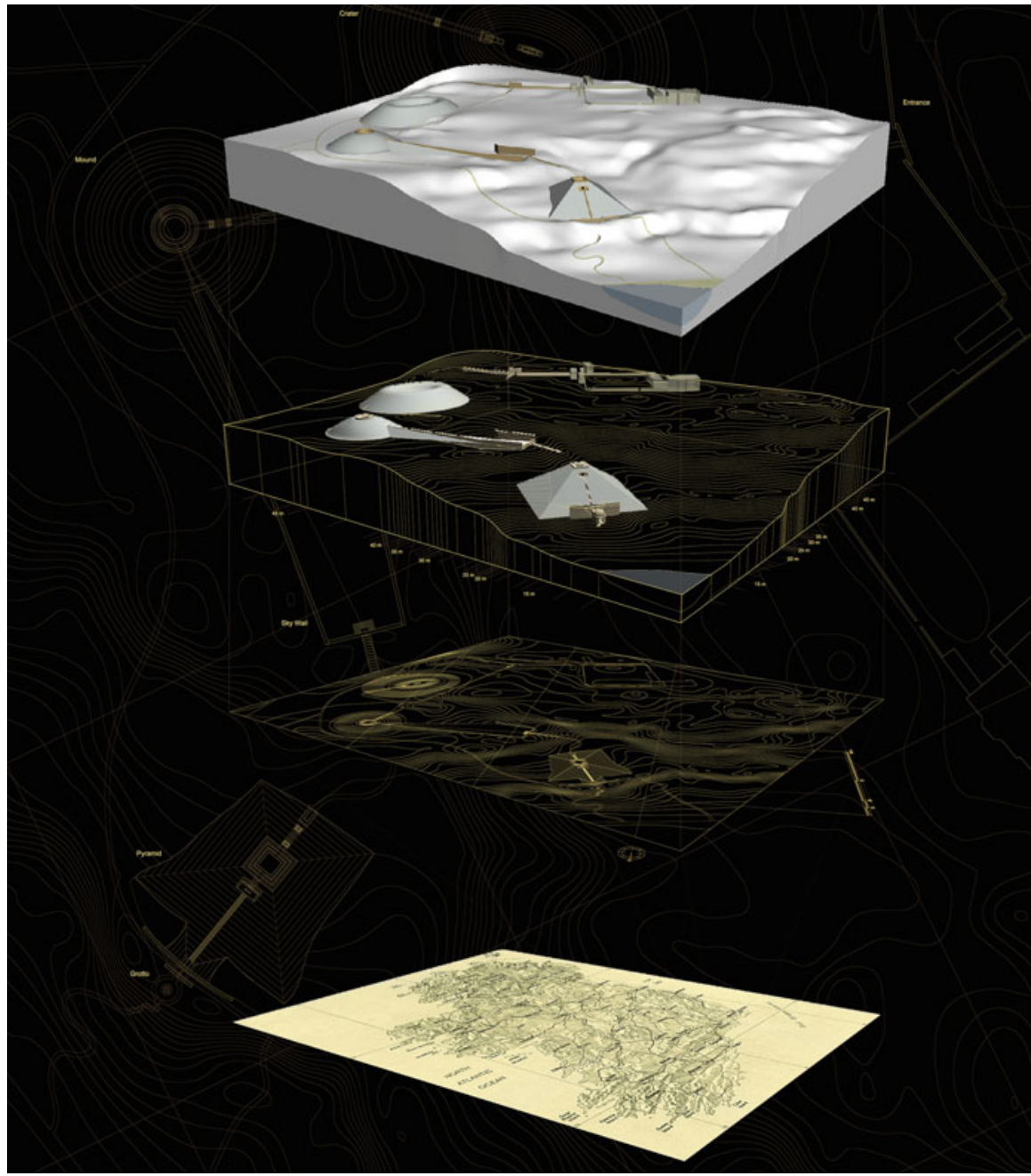

Fig. 22 James Turrell, the Irish Sky Garden complex, West Cork, 1989-1991. (Digital image by Francesco Bergamo, 2005)

by listening to the environment's response to their clicking with their tongues and mouths.

James Turrell turns the impossibility of total black for our sensation and perception, as an analogous to the impossibility of silence for John Cage, into a perceptual and cultural analytical tool, similarly to what a few other artists, philosophers, and scientists do in order to investigate the details of our interaction with the phenomenal world. Experiments on perception are usually conducted in a controlled environment, thus eliminating everyday stimuli, and the more is 


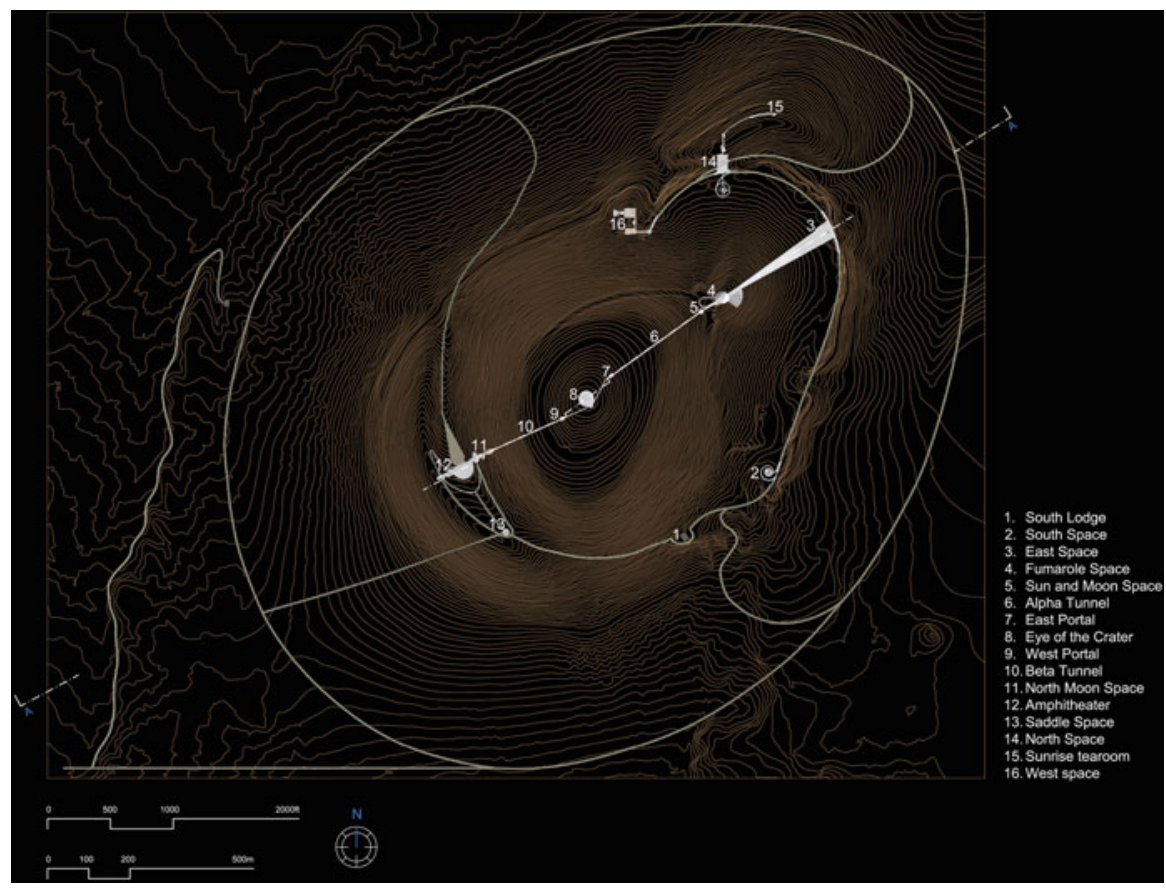

Fig. 23 James Turrell, the Roden Crater Project, Flagstaff. (Digital image by Francesco Bergamo/Imago Rerum, 2007)

taken away, the more it becomes possible to investigate very specific aspects, and sometimes something else emerges.

An art installation can thus become a sort of laboratory, a controlled set of conditions in which every visitor becomes the explorer of her own self. This is why James Turrell's work represents one of today's strongest connections between arts and science. Perceptual deceptions are here carefully produced by the interaction of the senses with the physical staging of light and darkness, but a strong symbolic component is always present, often related to the artist' own speculative interests.

The Dark Spaces are totally dark environments, generally soundproof, accessed through a path which also works as a filter from the outside world. They are quite simple closed rooms with no seemingly perceivable light. For this reason, it is impossible to provide photographs of most of them when they are active - which is to say when lights are off - with the exception of blurred photos of projections, taken with the shutter opened for hours.

The case here presented is Blind Sight (1992) (Fig. 25), built in Stockholm in 1994 and in Saitama in 1997. The figure shows the simple architectural configuration of the room, the position of the observer sitting in front of the projection, and the presence of a projector in a small space just under the visitor. 


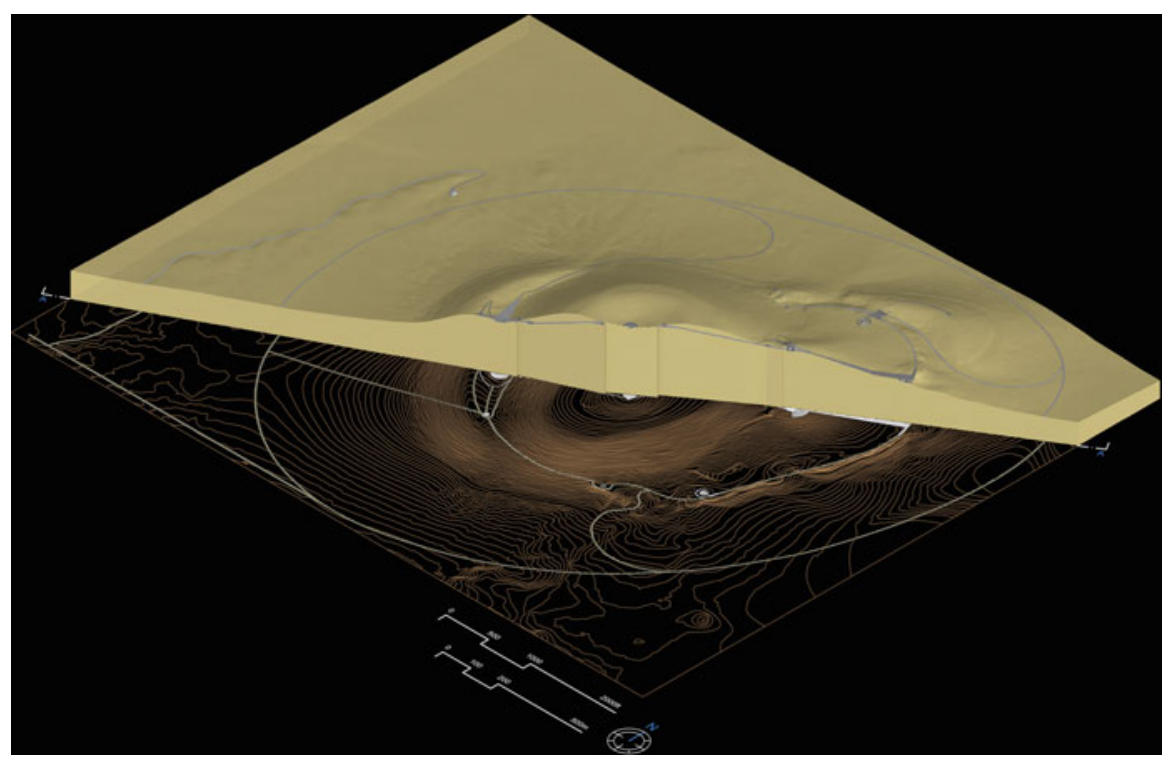

Fig. 24 James Turrell, the Roden Crater Project, Flagstaff. (Digital image by Francesco Bergamo/Imago Rerum, 2007)

To enter Blind Sight and reach the chair, the visitor crosses a threshold and climbs a winding, labyrinthine, painted black path, where her vision begins to get used to darkness. Once finally inside, she sits on the chair, assuming a position from which she will - in 10-15 min - be able to observe some geometric, very low intensity luminous projections, often in motion. In fact, once the visitor enters the installation, for the first $10 \mathrm{~min}$ circa her visual situation is conditioned by the images previously registered by the retina in the external environment. This is a very common experience, which happens every time someone enters a dark space coming from a bright environment, but it is usually considered with very little attention, because in everyday life a strong image is replaced immediately by another, seamlessly, for example, by turning on the light after having reached for the switch. As these after-images dissolve, the visual experience softens and the colored light projected from below upon the wall in front of the visitor, drawing blurred images, begins to blend in with the retinal memory. What happens is a sort of crossfading between memory and projection, between outer and inner - and interior - space, while the observer grows aware of her act of seeing. The space of the installation collapses, is deconstructed by shadows, loses its physical limits, and thus tends to coincide with the one sought and represented by the visitor to her own perception. The foreground-background relationship is absent, because the luminous figure is undefined, abstract, and borderless: there is no background in darkness, or everything becomes background. With the senses furtherly stimulated by the expectation of what is going to happen, since the viewer is contextually 


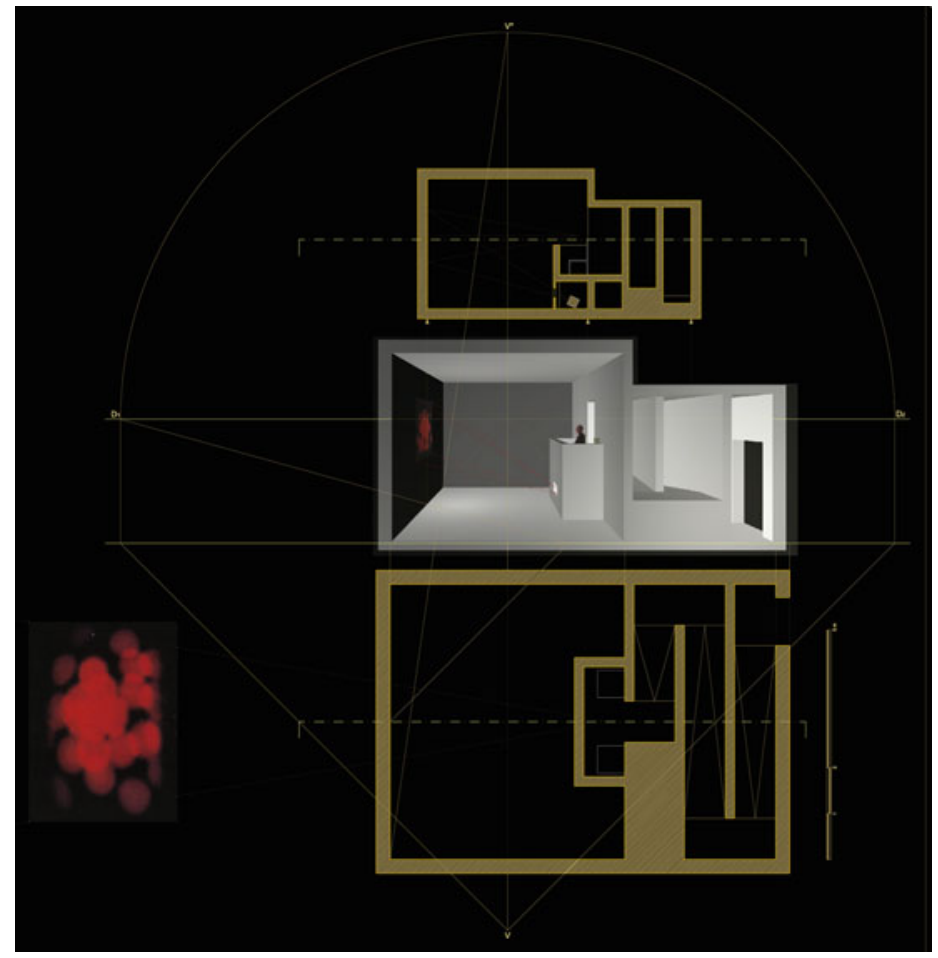

Fig. 25 James Turrell, Blind Sight, 1992. (Digital image by Francesco Bergamo, 2005)

engaged in the aesthetic domain of art, hallucinatory experiences are not unusual, especially when visitors stay inside for very long periods, as the artist suggests to do. The cause might be the same described by Oliver Sacks in the chapter titled "The Prisoner's Cinema" of his book Hallucinations: "the brain needs not only perceptual input but perceptual change, and the absence may cause not only lapses of arousal and attention but perceptual aberrations as well. Whether darkness and solitude is sought out by holy men in caves or forced upon prisoners in lightless dungeons, the deprivation of normal visual input can stimulate the inner eye instead, producing dreams, vivid imaginings, or hallucinations" (Sacks 2012, p. 34). If not stimulated by senses, the brain reacts by producing phosphenes, its own private luminous motion pictures, even in the case of diffused light as it happens in the Ganzfelds or Perceptual Cells (Fig. 26).

Turrell does not only aim at making the visitors aware of the psychological effects caused by particular regimes and arrangements of light and space, but he also wants the light to be perceived as much as possible as something tangible, as an unstable material whose characteristics and features can be described by Quantum Electrodynamics (cfr. Feynman 1985). 
Fig. 26 James Turrell, Boullée Boola, 1998. (Digital image by Francesco Bergamo, 2005)

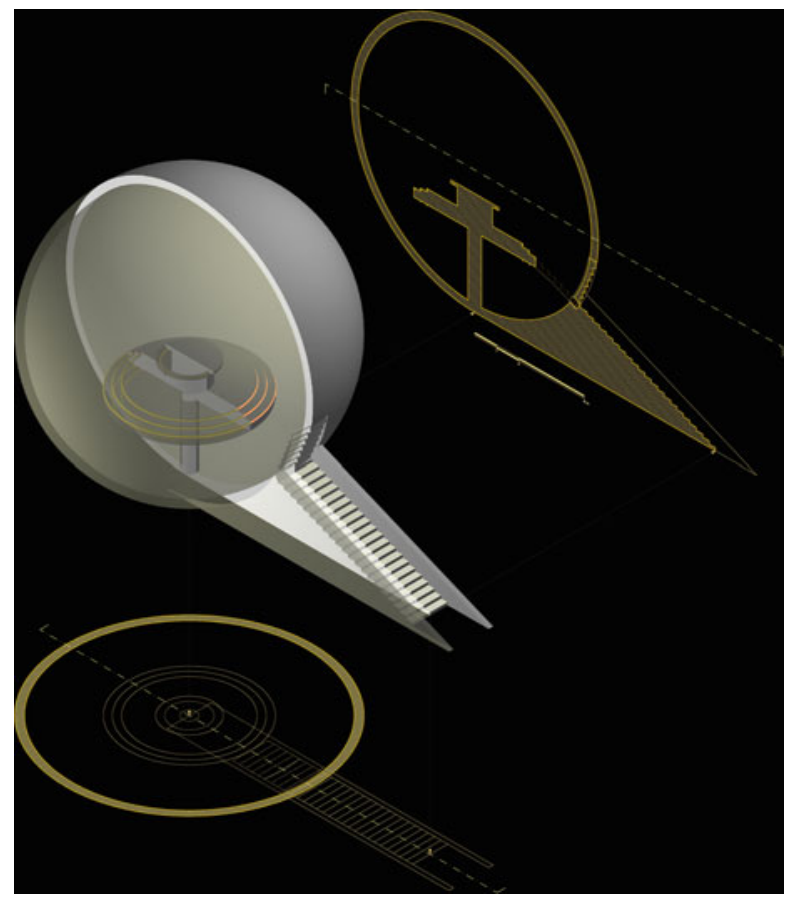

As for every other work by Turrell, the Dark Spaces are made to "see oneself seeing," somehow similarly to how the poetics of John Cage is about the awareness of listening. The initial act of climbing in suggests a sort of ascension into darkness: but this is not the infernal, underground darkness, undefined and dirty.

James Turrell's spaces are deliberately deceptive, to make the visitors focus entirely on their own perception: the usual, ecological reference points of everyday life are left outside, abandoned when crossing the threshold. Some of Olafur Eliasson's works are apparently similar to Turrell's. For example, if we compare Eliasson's projections (e.g., Corner Extension, 2000) to Turrell's cross-corner projections (Fig. 18a, b), one might think that they work in the same way: the perspectival deformation, or anamorphosis, of a simple geometrical shape made of light, projected on a wall, can make us perceive that shape as extending the wall beyond its corner, or as a solid polyhedron made of light hung in the corner. But Turrell hides the projector, leaves the visitor alone with the sole projection, and forces her to learn to understand what is happening, how what she sees can be possible, how it is made, and why her sight reacted that way. Eliasson does not hide anything: projectors, cables, sockets, everything is displayed and is part of the installation. He is more interested in the relation between the political and phenomenal levels of his works; thus, the visitor does not take a long time to understand the deception but must instead reflect upon the staged deception and is forced to inhabit the same space where the projectors and cables are, relate to 
them and become aware of how simple it is to artificially deceive human perception and to alter a human being's relation with the world.

There is no trace of mysticism in Eliasson's physical and material presences, while Turrell often compared his role as an artist to that of the bodhisattvas in the Buddhist tradition. He, an artist much familiar with light, offers to us his artistic devices, capable of making us "see ourselves seeing," taking a step towards literal and metaphorical illumination. But another symbolic interpretation seems to represent consistently the experience of a visitor in the Dark Spaces. This interpretation perfectly matches the chapter titled "The Cave and the Labyrinth" in René Guénon's Symbols of Sacred Science (Guénon 2004, pp. 193-201). After abandoning the viewer in the maze at the end of a dark labyrinth, the artist provides her with the tools to recover light with an unexpected awareness. The artwork is therefore a dispositive of initiation, the cave (the dark space where the visitor sits and slowly begin seeing projected light) being the place where the initiation is fulfilled, and the labyrinth (the access corridor) the path that leads to it and at the same time the obstacle that prevents the profanes from accessing it. Initiation is like a second birth, as is the passage from darkness to light, and the place where this happens is the cave. "The truth is that, far from being a place of darkness, the initiatic cave is illuminated from within, so that it is outside the cave on the contrary that darkness reigns, the profane world naturally being likened to the 'outer darkness' and the 'second birth' being at the same time an 'illumination"' (Guénon 2004, p. 196). In the cave, darkness is not terrifying nor sublime, but instead sweet and warm, just like the darkness that Jorge Luis Borges learns to accept as a gift at the end of his life: "this growing dark is slow and brings no pain" (Borges 1975).

While still inside a Dark Space, after having become familiar with the light, the visitor finds herself in the condition of leaving the cave and has to do it by retracing her steps, following backward (and downhill) the access path, finally crossing again in the opposite direction the threshold that separates the space of the installation from the "normal," everyday conditions of the outside. This apparently goes against the fact that, according to Guénon, the exit from the initiatic cave should be found upwards, or at least on the opposite side of the entrance. But Guénon also offers other possibilities for the path of initiation of Labyrinth and Cave and, in any case, independently from its form, it leads to a rebirth that is fulfilled with the epiphany of light.

Having to go back on one's own steps to get out of the cave and re-enter the world reinforces the presence of another symbolic dimension, suggested by the artist himself: the dreamlike. In Blind Sight as in most of the other Dark Spaces, darkness induces a condition of reverie, and more precisely of lucid dreaming, antithetical to that of the nightmare but nonetheless powerful. The almost-zero quantity of light produces the appearance of an almost-infinite space, which is also a space of infinite imaginative possibilities. Expectation and imagination here should anyway prevent from that fear of the dark which is common for children. "We would be wrong to interpret children's night-time terrors as the result of excessive imagination. [ ... ] A child rapidly runs up against the limits of his imagination, then finds himself before the most radical, the most terrifying unknown. He finds himself at the gates of the 
infra-world, and there perceives the real danger of being snapped up by nothingness, of seeing the few certainties acquired during his early years shattered to pieces and sinking into the pitch-black waters of a groundless world" (Bonnet 2017, pp. 7-8).

The state of self-awareness induced by the artwork thus reinforces a very specific kind of dreamlike dimension, that of the aforementioned lucid dreams, or the condition in which the sleeping person is conscious of her dreaming state and is able to control her actions and will, in the dreams as much as in real life. Achieving this awareness can be tiring and requires dedication, but the prize is, just as in any initiatic path, enlightenment. A perfect description of this specific enlightenment can be found in Elémire Zolla's words about Milarepa's ability to control his own dreams: "extreme perfection smiles when attention focuses on the particular, dazzled light that outlines the objects in the dream [... ]. It is understood that that light is the Sun of truth, of inner life, equidistant both from the darkness of dreamless sleep and from the raw glare of the outer sun. At this point one is, literally, illuminated" (Zolla 1992, p. 74).

In László Krasznahorkai's novels (e.g., Krasznahorkai 2016), as much in many cultural expressions of Western culture, shadows are often related to the dissolution of order, whose counterpart is the emergence of chaos, which for Krasznahorkai anyway can activate a different, even superior state of knowledge than that of light, order, and creation. The order of human representation is weaker than the apparent chaos of nature, subject to the law of entropy but with its own, superior, and notanthropocentric logic. Something very similar can be found in the movies by the filmmaker who mostly resonates with Krasznahorkai, Béla Tarr. In The Turin Horse (2011), directed by Tarr with Ágnes Hranitzky, the spectators, in a modern Plato's cave which is the cinema (cfr. Chris Marker's The Owl's Legacy, 1989), assist to a sort of anti- or counter-creation, where the projected images of few human beings and living things are more and more immersed in and exposed to shadows and darkness, being slowly deprived by anything but their own immanence.

This is the contrary of what happens with Turrell: his darkness aims at expanding perception and organizing sensation, reconnecting humans with the harmonic geometry of the Spheres. The hallucinatory and dreamlike experiences given within Blind Sight act both on an objective and a very subjective level: even though sensation is physiologically induced by actual physical stimuli, it resonates differently with different brains. "Imagination always participates in the recognition of a known world, even when it magnifies it and renders it marvelous. So the space of representation, however subversive it may be, is always a space of order" (Bonnet 2017, p. 11).

\section{Conclusion}

The two artists and their works here presented are apparently and effectively very different from each other. Piero della Francesca was deeply rooted in the perspectival Western tradition at its beginning and in the Christian world, for which he set in the Brera Altarpiece a narrative that contains an enigma of lights and 
shadows. James Turrell is a contemporary American artist who has learnt the lesson of the reconciliation between East and West: he masters perspective but is not afraid of quitting it in the Dark Spaces, avoiding any narrative to provoke pure contemplation of the viewer's own secret perception.

In both cases, light and darkness need each other to make sense to us, to engage us, and to change our way to see the world and become aware of our own interaction with it. In both, a geometrical conception of light is employed with symbolic meanings that are conveyed through rigorously organizing and tuning the experience of the viewer.

In all of the works by the two artists, art is a way to understand the world, a cultural context where basic and applied research meet, beyond the rules of academic contexts. In Piero, art and science are clearly the same thing: the innovation he presents in his writings can be found in his paintings and, the other way around, in his paintings he experiments in practice his theoretical advances. Turrell was one of the most active participants involved in The Art and Technology program (A\&T) at the Los Angeles County Museum of Art (LACMA) during the late 1960s: there, he developed with scientists some spatial devices for immersing viewers in complete perceptual fields, the Ganzfelds.

Piero della Francesca wants to paint complex shadows projected onto complex architectural forms, but he still cannot rely on a correct and universal theoretical model which will be partly defined only later by Guidobaldo del Monte in 1600 the first universal and correct method for drawing shadows projected by the Sun in perspective will be described by Jean-François Niceron in Thaumaturgus Opticus only in 1646 (cfr. Bergamo 2013, pp. 418-424), almost two centuries after the Brera Altarpiece. Piero solves the problems by summing shadows outlines coming from different light sources, and the symbolic and technical reasons of his choice still need further investigation.

James Turrell, instead, is obviously aware of shadow projection theories, methods, and techniques but chooses instead to work by subtracting any figurative and architectural element. He does not represent an architectural space in a painting, but instead his work for the Dark Spaces consists of the architectural space plus the light projection themselves. While in Piero's Sacred Conversation space appears in its perspectival and architectural representation, in Turrell's Blind Sight the room disappears in darkness, making space to the sole luminous stimuli.

Many things in human history and culture have changed in more than 500 years; therefore, art as geometric research in the late Nineteenth Century is much different from what it was in the early Renaissance. But Turrell's and Piero's works speak of the same animal species on the same planet, still dealing with the same questions which are at the same time physical, technical, and metaphysical. 


\section{References}

Adcock CE (1990) James Turrell. The art of light and space. University of California Press, Berkeley

Aromberg Lavin M (1972) Piero della Francesca: the flagellation. Penguin, New York

Battisti E (1974) Bramante, Piero e Pacioli ad Urbino. In: VV. AA., Studi Bramanteschi. De Luca Editore, Milano/Urbino/Rome

Berenson B (1950) Piero della Francesca o dell'arte eloquente. Electa, Milan

Bergamo F (2013) Skiagrafia, cosmologia kepleriana e anamorfosi dell'umano. Sull'Appendice sulla Luce e le Ombre nel Thaumaturgus Opticus. In: De Rosa A, Niceron J-F (eds) Prospettiva, catottrica e magia artificiale. Aracne, Rome

Bonnet FJ (2017) The infra-world. Urbanomic, Falmouth

Borges JL (1975) In praise of darkness. Allen Lane, London

Butterfield J (1993) The art of light + space. Abbeville Press, New York

Carter R, Wittkower R (1953) The perspective of Piero della Francesca's "flagellation". J Warburg Courtauld Inst XVI:292-302

Clark K (1951) Piero della Francesca. Phaidon, London

De Rosa A (1993) Geometrie dell'ombra. Storia e simbolismo della teoria delle ombre. Città Studi edizioni, Milano

De Rosa A (2004) Tra luce e ombra. Il Poligrafo, Padua

De Rosa A (ed) (2007) James Turrell. Geometrie di luce. Roden Crater Project. Electa, Milan

Di Teodoro FP (1996) La Sacra Conversazione di Piero della Francesca. TEA-Arte, Milan

Feynman R (1985) QED: the strange theory of light and matter. Princeton University Press, Princeton

Gann K (2010) No such thing as silence: John Cage's 4' 33". Yale University Press, New Haven

Guénon R (2004) Symbols of sacred science. Sophia Perennis, New York

Krasznahorkai L (2016) War and war. Tuskar Rock, London

Maltese C (1974) Architectura "ficta" 1472 circa. In: VV. AA., Studi Bramanteschi. De Luca Editore, Milan/Urbino/Roma

Meiss M (1954) Ovum Struthionis, symbol and allusion in Piero della Francesca's Montefeltro Altarpiece. In: Miner DE (ed) Studies in art and literature for Belle da Costa Greene. Princeton University Press, Princeton, p 92

Meiss M, Jones TC (1966) Once again Piero della Francesca's Montefeltro Altarpiece. In: The art bulletin, vol XLVIII, no. 2. Taylor \& Francis, London, pp 203-211

Oursel R (1986) Architettura Romanica. Jaca Book, Milan

Palmer SE (1999) Vision science. Photons to phenomenology. The MIT Press, Cambridge, MA/London

Rella F (1986) Il paesaggio della tecnica. In: Gran Bazar, no. 12/1. Edizioni Syds-Italia, Milan, p 28

Sacks O (2012) Hallucinations. Alfred A. Knopf, New York

Torres AM (ed) (2004) James Turrell. IVAM, Valencia

Trevisani F (1996) La pala di San Bernardino: indagini preliminari alla problematica della carpenteria. In: Dalai Emiliani M, Curzi V (eds) Atti del Convegno Internazionale di Studi su Piero della Francesca, Urbino, Arezzo, Sansepolcro, 4-12 Ottobre 1992. Marsilio, Venice, pp 183-193

Wilde J (1929) La Pala di San Cassiano. In: Jahrbuch der Kunsthistorischen Sammlungen. A. Schroll \& Co., Wien, n. s., III

Zolla E (1992) Uscite dal mondo. Adelphi, Milan 


\section{Suggested Further Reading}

Casalini F (1968) Corrispondenza fra teoria e pratica nell'opera di Piero della Francesca. In: L'Arte I, n. s. Nuovi Quaderni di Capestrano S.R.L., Rome, pp 62-95

De Rosa A, D'Acunto G (2002) La vertigine dello sguardo. Tre saggi sulla rappresentazione anamorfica. Cafoscarina, Venice

Farinelli F (1991) In-traduzione. In: Olson G (ed) Linee senza ombra. Theoria edizioni, Naples/Rome

Filed JV (2005) Piero Della Francesca: a mathematician's art. Yale University Press, Yale

Giménez C, Trotman N, Zajonc A (2013) James Turrell. Guggenheim Museum Publications, New York

Govan M, Kim CY (2013) James Turrell. A retrospective. Prestel Publishing, New York/London

Londei EF (1991) La scena della "Flagellazione" di Piero della Francesca. La sua identificazione con un luogo di Urbino del Quattrocento. In: Bollettino d'Arte, n. 29. Istituto Poligrafico dello Stato, Rome

Meiss M (1941) A documented altarpiece of Piero della Francesca. In: The art bulletin, no. 23. Taylor \& Francis, London, pp 62-65

Migliari R (2017) De Prospectiva Pingendi di Piero della Francesca nell'originale volgare e nella versione latina, vol III. Istituto Poligrafico e Zecca dello Stato, Rome

Noever P (ed) (2001) James Turrell. The other horizon. Hatje Cantz, Berlin/Stuttgart

Sinnreich U (ed) (2009) James Turrell. Geometrie des Lichts. Hatje Cantz, Berlin/Stuttgart

Stoichita VI (1997) A short history of the shadow. Reaktion Books, London

Witham L (2014) Piero's light: in search of Piero Della Francesca: a renaissance painter and the revolution in art, science, and religion. Pegasus Books, New York 